\title{
High-resolution models of tropospheric delays and refractivity based on GNSS and numerical weather prediction data for alpine regions in Switzerland
}

\author{
Karina Wilgan $^{1,2} \cdot$ Alain Geiger $^{1}$
}

Received: 29 March 2018 / Accepted: 20 September 2018 / Published online: 1 October 2018

(c) The Author(s) 2018

\begin{abstract}
The tropospheric delay of a microwave signal affects all space geodetic techniques. One possibility of modeling the delay is by introducing tropospheric models from external data sources. In this study, we present high-resolution models of tropospheric total refractivity and zenith total delay (ZTD) for the alpine area in Switzerland. The troposphere models are based on different combinations of data sources, including numerical weather prediction (NWP) model COSMO-1 with high spatial resolution of $1.1 \mathrm{~km} \times 1.1 \mathrm{~km}$, GNSS data from permanent geodetic stations and GPS L1-only data from low-cost permanent stations. The tropospheric parameters are interpolated to the arbitrary locations by the least-squares collocation method using the in-house developed software package COMEDIE (Collocation of Meteorological Data for Interpretation and Estimation of Tropospheric Pathdelays). The first goal of this study is to validate the obtained models with the reference radiosonde and GNSS data to show the improvement w.r.t. the previous studies that used lower resolution input data. In case of total refractivity, the profiles reconstructed from COSMO-1 model show the best agreement with the reference radiosonde measurements, with an average bias of $1.1 \mathrm{ppm}(0.6 \%$ of the total refractivity value along a vertical profile) and standard deviation of $2.6 \mathrm{ppm}$ $(1.6 \%)$ averaged from the whole profile. The radiosondes are assimilated into COSMO-1 model; thus, a high correlation is expected, and this comparison is not independent. In case of ZTD, the GNSS-based model shows the highest agreement with the reference GNSS data, with an average bias of $0.2 \mathrm{~mm}(0.01 \%)$ and standard deviation of $4.3 \mathrm{~mm}(0.2 \%)$. For COSMObased model, the agreement is also very high, especially compared to our previous studies with lower resolution NWPs. The average bias is equal to $-2.5 \mathrm{~mm}(0.1 \%)$ with standard deviation of $9.2 \mathrm{~mm}(0.5 \%)$. The second goal of this study is to test the feasibility of calculating high-resolution troposphere models over a limited area from coarser data sets. We calculate the ZTD models with spatial resolution of $20 \mathrm{~m}$ for a test area in Matter Valley. We include the information from the low-cost GPS stations (X-Sense), to also assess the performance and future usability of such stations. We validate the models based on three data sources w.r.t. the reference GNSS data. For the station located inside the area of the study, the models have an agreement of few $\mathrm{mm}$ with the reference data. For stations located further away from the study area, the agreement for X-Sense is smaller, but the standard deviations of residuals are still below $15 \mathrm{~mm}$. We consider also another factor of evaluating the high-resolution models, i.e., spatial variability of the data. For designing a GNSS network, also for the tropospheric estimates, the height variability of the network may be as important as the horizontal distribution. The GNSS-based models are built from the coarsest network; thus, their variability is the lowest. The variability of X-Sense-based stations is the highest; thus, such data may be suitable for building troposphere models for very high-resolution applications.
\end{abstract}

Keywords Zenith tropospheric delay · Refractivity · Numerical weather prediction · GNSS · InSAR · Alpine regions · Low-cost L1-only GPS

Karina Wilgan

kwilgan@ethz.ch

1 Institute of Geodesy and Photogrammetry, ETH Zürich, Robert-Gnehm-Weg 15, HPV H51, 8093 Zürich, Switzerland
2 Institute of Geodesy and Geoinformatics, Wrocław University of Environmental and Life Sciences, Grunwaldzka 53, 50-357 Wrocław, Poland 


\section{Introduction}

One of the main limitations of all space-borne microwave signal processing techniques is the atmospheric delay. The signal is affected by the free electron content in the ionosphere and by the air molecules and water vapor in the electrically neutral atmosphere. The space-borne microwave techniques, in principle Global Navigation Satellite Systems (GNSS), Very Long Baseline Interferometry (VLBI) or Synthetic Aperture Radar Interferometry (InSAR), are all subjected to the atmospheric delay. In this study, we focus on the neutral atmosphere delay. Neutral atmosphere consists of troposphere (up to approx. $9 \mathrm{~km}$ above the poles and $16 \mathrm{~km}$ above the equator) and stratosphere + mesosphere (up to approx. $80 \mathrm{~km}$ above the Earth's surface). The meteorological parameters in the troposphere contribute to the majority of the total delay; thus, in the scope of this study, we call the delay 'tropospheric.' We present high-resolution models of tropospheric parameters, namely the total refractivity and zenith tropospheric delay (ZTD) based on external data sources. For various applications, the $Z T D$ can be then mapped into the direction of the satellite to obtain the slant delay.

The application of high-resolution external troposphere models in GNSS processing, especially in Precise Point Positioning (PPP) technique, has been proven to enhance the coordinates accuracy and to shorten the convergence time of the position solution (Wilgan et al. 2017b; Zheng et al. 2017; Lu et al. 2017; de Oliveira et al. 2017). In this study, we focus on building the troposphere model for future highresolution applications, such as for the space-borne InSAR technique, where the atmospheric effects are still one of the major challenges due to the different states of atmosphere, especially different water vapor densities, during two acquisitions (Lambiel et al. 2008). Due to its high variability, the water vapor is the most difficult meteorological parameter to model. Tropospheric effects can cause signals in interferograms that are often much larger than the tectonic signals of interest (Hooper et al. 2012; Bekaert et al. 2015a).

There are two commonly employed approaches to eliminate the tropospheric impact on InSAR images, namely data-driven and model-driven approaches. In the data-driven approach, the atmospheric phase corrections are estimated from the high-resolution interferometric phase itself. For example, in persistent scatterer interferometry (PSI), the goal is to identify coherent targets for which the atmosphereinduced phase can be isolated from other phase components, mainly residual topography and deformation. Different methods, such as linear regression (Wicks et al. 2002), linear or power law (Bekaert et al. 2015a, b) or kriging (Siddique et al. 2018), have been suggested to model the spatial dependence of tropospheric delays and interpolate them over the entire scene. However, finding the coherent points can be very chal- lenging in non-urban areas, such as mountainous regions. In the model-driven approach, the tropospheric corrections are modeled based on external data sources, for example numerical weather prediction (NWP) models (Hobiger et al. 2010; Nico et al. 2011; Mateus et al. 2013; Kinoshita et al. 2013), GNSS data (Williams et al. 1998; van der Hoeven et al. 2002; Foster et al. 2006) or spectrometers, such as Medium Resolution Imaging Spectrometer (MERIS) on board the ENVISAT satellite or Moderate Resolution Imaging Spectroradiometer (MODIS) on board the Terra and Aqua satellites (Puysségur et al. 2007; Li et al. 2009; Bekaert et al. 2015b). The limitation of the model-driven approach is too coarse distribution of the external data sources such as GNSS or NWP, which is often of several or tens of kilometers while the resolution of the InSAR pixels is of several or tens of meters. On the other hand, the spectrometers can provide useful information only in cloud-free conditions (Bekaert et al. 2015b).

This paper is a continuation of the development of tropospheric models conducted in Hurter and Maier (2013) and Wilgan et al. (2017a, b). In these previous studies, the authors reconstructed the tropospheric parameters in Switzerland using the least-squares collocation software COMEDIE (Collocation of Meteorological Data for Interpretation and Estimation of Tropospheric Pathdelays) developed at ETH Zurich (Eckert et al. 1992a, b; Troller 2004; Hurter and Maier 2013; Wilgan et al. 2017a). In Hurter and Maier (2013), the wet refractivity profiles were calculated and interpolated for the location of the aerological station of MeteoSwiss (operational radiosonde launches twice a day). The models were based on GPS data, ground-based meteorological measurements and radio occultations. In Wilgan et al. (2017a), the total refractivity profiles for Switzerland were reconstructed from ground-based meteorological and GNSS data. Moreover, the refractivity profiles as well as ZT Ds were calculated from NWP and GNSS data for Poland. Up to date, there has been no study on the ZT Ds derived from the leastsquares collocation software COMEDIE in the Swiss Alps.

The Alps constitutes about $60 \%$ of the Swiss total area. It is especially important, but also challenging to provide reliable measurements in the high mountains for monitoring all the changes in the Alps, such as avalanches, deformations, rock glaciers activity, landslides. Monitoring of hazards due to the slope instabilities is crucial, as they affect about $6 \%$ of Swiss territory (Raetzo et al. 2002; Lateltin et al. 2005). It has been demonstrated that the InSAR technique is useful for calculation of deformations, rock glacier displacements or landslides in the Alps (Kääb et al. 2005; Lambiel et al. 2008; Strozzi et al. 2013), although InSAR still struggles with inaccurate atmospheric phase corrections, especially in mountainous areas. In this paper, we present troposphere models that can be used in the future to remove the atmospheric effect on InSAR images in the mountainous regions. Due to the high spatial resolution of the models, we suggest 
the application for InSAR, but the spectrum of applications may be much wider. The models can be made suitable for all microwave techniques.

This introduction is followed by Sect. 2, which characterizes the data sources employed in building the troposphere models. Section 3 describes the interpolation methodology, namely the least-squares collocation technique. Section 4 validates the methodology with respect to the reference radiosonde measurements and GNSS data. Section 5 presents the tropospheric models for a limited alpine area in Matter Valley. Section 6 investigates the spatial variability of particular data sources, and Sect. 7 summarizes the study.

\section{Data sources}

The troposphere models are calculated from three data sources: 2.1) NWP model COSMO-1 (Consortium for Smallscale Modeling ${ }^{1}$ ), 2.2) GNSS delays from geodetic permanent stations and 2.3) GPS delays from low-cost permanent stations in Matter Valley. The data period used for comparisons is August 1-September 30, 2016. The chosen period is summer, because in this season, the water vapor variability is the highest; thus, the tropospheric delays are the most difficult to model. Plots showing the periodical behavior of water vapor can be found, for example, in Alshawaf et al. (2017). Moreover, to detect temporal changes of the topography using the InSAR technique, the period should be snow-free (Delaloye et al. 2007).

\subsection{Numerical weather prediction model COSMO-1}

The COSMO-1 model is provided by the Swiss Federal Office of Meteorology and Climatology (MeteoSwiss ${ }^{2}$ ). The COSMO-1 model is calculated for the entire alpine region on a grid with $1.1 \mathrm{~km} \times 1.1 \mathrm{~km}$ horizontal resolution. Figure 1 shows the topography of the model domain. We use the configuration with 65 vertical layers up to $12 \mathrm{~km}$ above mean sea level (amsl). The layers reach only $12 \mathrm{~km}$, because the lateral relaxation zone and the model levels that are situated in the sponge layer at the top of atmosphere were omitted for quality reasons (personal communication with MeteoSwiss). The heights of COSMO-1 model are geopotential, which is a common way to represent heights in NWP models. The heights of GNSS stations and terrain points are usually given as orthometric or normal. We convert the geopotential heights of COSMO- 1 into the geometric heights according to the formulas given in Vedel (2000).

The COSMO-1 model assimilates many meteorological observations: wind, temperature and humidity from

\footnotetext{
1 www.cosmo-model.org.

2 www.meteoswiss.admin.ch.
}

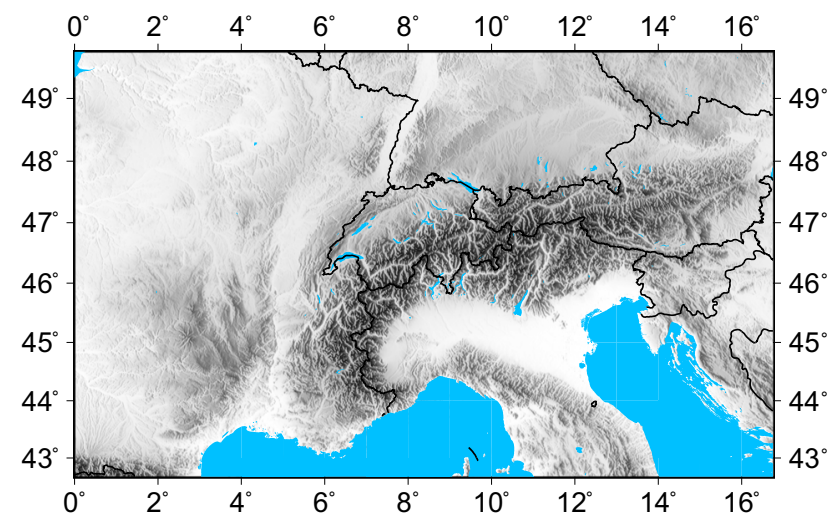

Fig. 1 COSMO-1 modeling domain, which covers the entire alpine region with Switzerland in the center

radiosonde measurements; temperature and wind from aircraft observations; wind profiler observations; surface pressure and $2 \mathrm{~m}$ dew point temperature measurements; and radar surface precipitation from the Swiss Radar Network. No GNSS data have been assimilated into COSMO-1 model yet (personal communication MeteoSwiss); thus, the comparisons between COSMO-1 and GNSS products are independent. Assimilation of the GNSS data into COSMO-1 model could have had a positive impact on the agreement with GNSS data (Vedel and Huang 2004; Boniface et al. 2009; Zus et al. 2011; Bennitt and Jupp 2012), although an interpolation method of the NWP outputs would still be required.

In this study, we use the meteorological parameters: air pressure $p$, temperature $T$ and water vapor partial pressure $e$ from COSMO-1 analysis with $1 \mathrm{~h}$ resolution. For post-processing techniques such as InSAR, using the NWP analyses instead of forecasts is sufficient. We calculate the total refractivity $N_{\text {tot }}$ from COSMO-1 meteorological parameters for every vertical level of the model using the formula of Essen and Froome (1951):

$N_{\text {tot }}=k_{1} \cdot \frac{p-e}{T}+k_{2} \cdot \frac{e}{T}+k_{3} \cdot \frac{e}{T^{2}}$,

where $k_{1}=77.689 \mathrm{~K} \cdot \mathrm{hPa}^{-1}, k_{2}=71.2952 \mathrm{~K} \cdot \mathrm{hPa}^{-1}$ and $k_{3}=375463 \mathrm{~K}^{2} \cdot \mathrm{hPa}^{-1}$ are the 'best average' refractivity coefficients from Rüeger (2002) empirically determined for the L-band frequencies. Furthermore, we calculate the ZT D as an integral of the total refractivity:

$Z T D=10^{-6} \int_{\text {zenith direction }} N_{\text {tot }}(s)$ ds.

In our discrete case, Eq. 2 can be approximated as:

$$
Z T D_{\mathrm{COSMO}} \approx 10^{-6} \cdot \sum_{i=1}^{\text {TOP-1 }} \frac{N_{i}+N_{i+1}}{2} \cdot \Delta s_{i}
$$


where $N_{i}$ is the total refractivity at the $\mathrm{i}$-th level, $T O P$ is the number of levels of COSMO- 1 model and $\Delta s_{i}$ is the geometric distance between $i-$ th and $(i+1)$-th layer of the model. To include the delay above the top layer of the model, we add the delay calculated using the Saastamoinen (1973) formula from the parameters of the topmost layer:

ZT D $D_{\mathrm{TOP}}=0.002277 \cdot\left(p_{\mathrm{TOP}}+\left(\frac{1255}{T_{\mathrm{TOP}}}+0.05\right) \cdot e_{\mathrm{TOP}}\right)$,

where $p_{\mathrm{TOP}}, T_{T O P}$ and $e_{\mathrm{TOP}}$ are the meteorological parameters from the topmost level of the model. The total delay based on the COSMO-1 model is expressed as:

$Z T D_{\text {total }}=Z T D_{\mathrm{COSMO}}+Z T D_{\mathrm{TOP}}$

\subsection{GNSS data}

The GNSS ZT Ds are calculated from permanent networks: the Automated GNSS Network for Switzerland (AGNES) complemented with several permanent stations from other national networks deployed and operated by the Swiss Federal Office of Topography (swisstopo ${ }^{3}$ ) and permanent GNSS network of ETHZürich installed in the alpine region of Valais within the framework of the project Coupled Seismogenic Geohazards in Alpine Regions $\left(\mathrm{COGEAR}^{4}\right)$. In total, we use the data from 63 stations from all networks (55 AGNES+ and 8 COGEAR stations), all processed by swisstopo. Figure 2 shows the locations of the stations from these two networks for the whole Switzerland (top) and for the Valais region (bottom). The average inter-distance between stations is $17.5 \mathrm{~km}$ for the whole network of Switzerland and $12.2 \mathrm{~km}$ for the selected 11 stations in Valais. The post-processed, doubledifferenced GNSS data are provided by swisstopo in the form of a weekly coordinate/troposphere solutions generated by AGNES BPE (Bernese Processing Engine). The ZT Ds as well as horizontal gradients are estimated with $1 \mathrm{~h}$ resolution from GPS and GLONASS observations using a development version 5.3 of Bernese software (Dach et al. 2015). The cutoff elevation angle is set up to $3^{\circ}$, and the mapping function is GMF (Global Mapping Function).

\subsection{X-Sense low-cost GPS stations}

The X-Sense project was a part of nano-tera.ch ${ }^{5}$ program of Swiss National Science Foundation (Beutel et al. 2011). The aim of this project was to investigate instabilities of

\footnotetext{
3 www.swisstopo.admin.ch.

${ }^{4}$ www.mpg.igp.ethz.ch/research/geomonitoring/cogear-gnssmonitoring.html.

${ }^{5}$ http://nano-tera.ch/projects/227.php.
}

alpine mountain slopes using various sensors and methodologies. Within this project, a set of 32 low-cost L1-only GPS stations was installed within an area of approximately $7 \mathrm{~km} \times 7 \mathrm{~km}$ in the Matter Valley. The topography of the area varies from $1300 \mathrm{~m}$ amsl in the valley to around $3700 \mathrm{~m}$ amsl in the mountains. The X-Sense stations are located at heights between $2326 \mathrm{~m}$ and $3159 \mathrm{~m}$ amsl. Most of the stations are located in a cluster in the northeast part of the area. Figure 2, bottom, white rectangle, shows the locations of the stations marked in green, and Fig. 3 shows the topography of the selected area with marked X-Sense stations. The ZT Ds are estimated without horizontal gradients with $1 \mathrm{~h}$ resolution using Bernese version 5.2 software (Dach et al. 2015). The mapping function is Niell, and the cutoff elevation angle is set to $10^{\circ}$, because of a possible signal obstruction due to the elevated peaks. The X-Sense stations are L1-only; thus, the $Z T D$ s are calculated in a relative sense (double differences) referenced to the COGEAR station RAND, which is shown as a pink dot in Fig. 3. The baseline starts with RAND for the stations in the west and one of the stations in the main batch (RD01). The rest of the main cluster is relative to RD01.

\section{Least-squares collocation method}

Models of $Z T D$ and total refractivity are calculated from the external data sources applying the least-squares collocation technique by the software COMEDIE. In the collocation technique, each measurement is divided into the deterministic part, the correlated stochastic part (signal) and the uncorrelated stochastic part (noise). With the estimated coefficients of the deterministic part and the signal, the considered parameters such as $Z T D$ or refractivity can be computed at any given position and time. The main trend of the considered variables in the collocation technique comes from the deterministic part, while the possibility of high resolution as well as the feasibility of predicting values comes from the signal. The following formula is used to describe the deterministic model of ZTD:

$$
\begin{aligned}
\operatorname{ZTD}(x, y, z, t)= & {\left[Z T D_{0}+a\left(x-x_{0}\right)+b\left(y-y_{0}\right)\right.} \\
& \left.+c\left(t-t_{0}\right)\right] \cdot e^{-\frac{z-z_{0}}{H_{0}}},
\end{aligned}
$$

where $x_{0}, y_{0}$ are the Swiss projected coordinates LV03 (Landesvermessung introduced in 1903), $z_{0}=0$ is the orthometric height and $t_{0}$ is the time of the reference point, whereas $x, y, z, t$ are the projected coordinates, orthometric height and time of the investigated point, $Z T D_{0}$ is the $Z T D$ at a reference position and time, $H_{0}$ is the scale height and $a, b, c$ are the gradient parameters in $x, y$ and time, respectively. The parameters $Z T D_{0}, H_{0}, a, b, c$ are the unknowns in the collocation procedure and are estimated in a least-squares sense 
Fig. 2 Permanent GNSS stations locations in Switzerland (top) and Valais (bottom). The topographic data are taken from the NASA ASTER Global

Digital Elevation Map (GDEM). The white rectangle denotes the area of the case study in Matter Valley

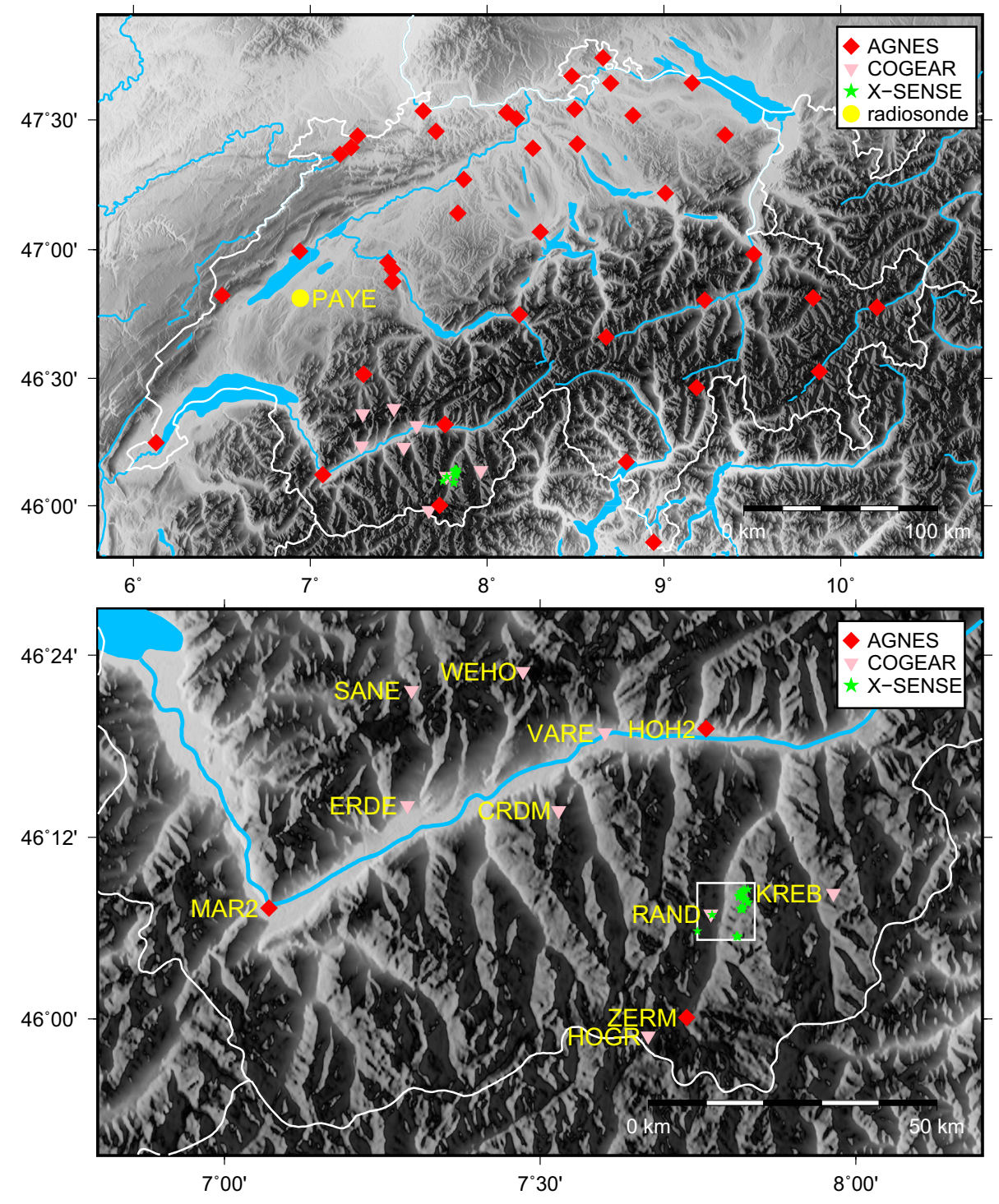

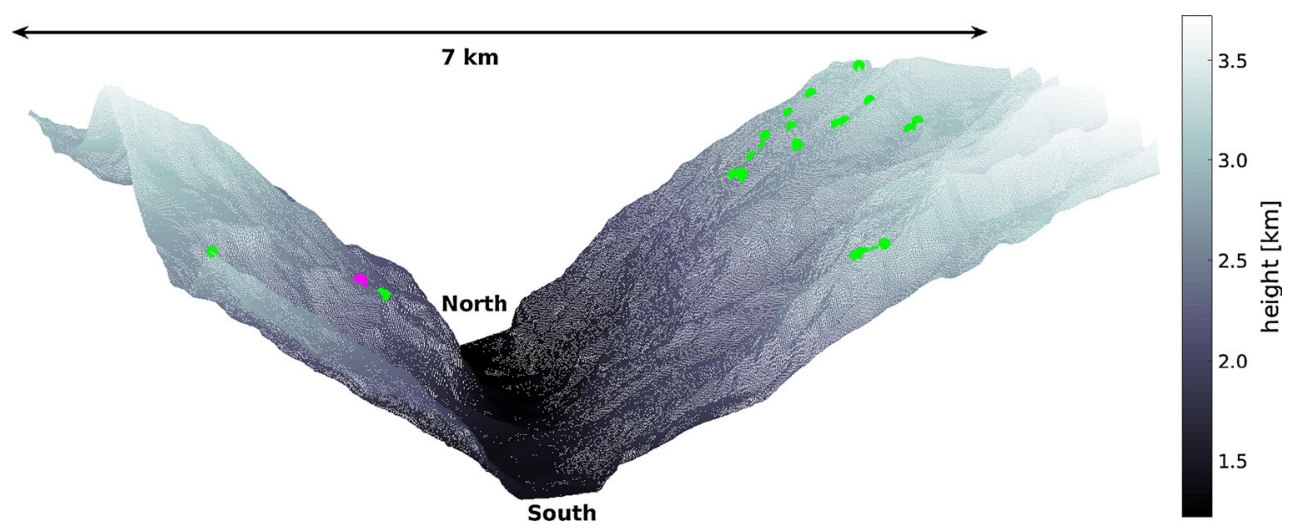

Fig. 3 Distribution of X-Sense stations in the Matter Valley. Green dots denote X-Sense stations, and the pink dot denotes the COGEAR station RAND 

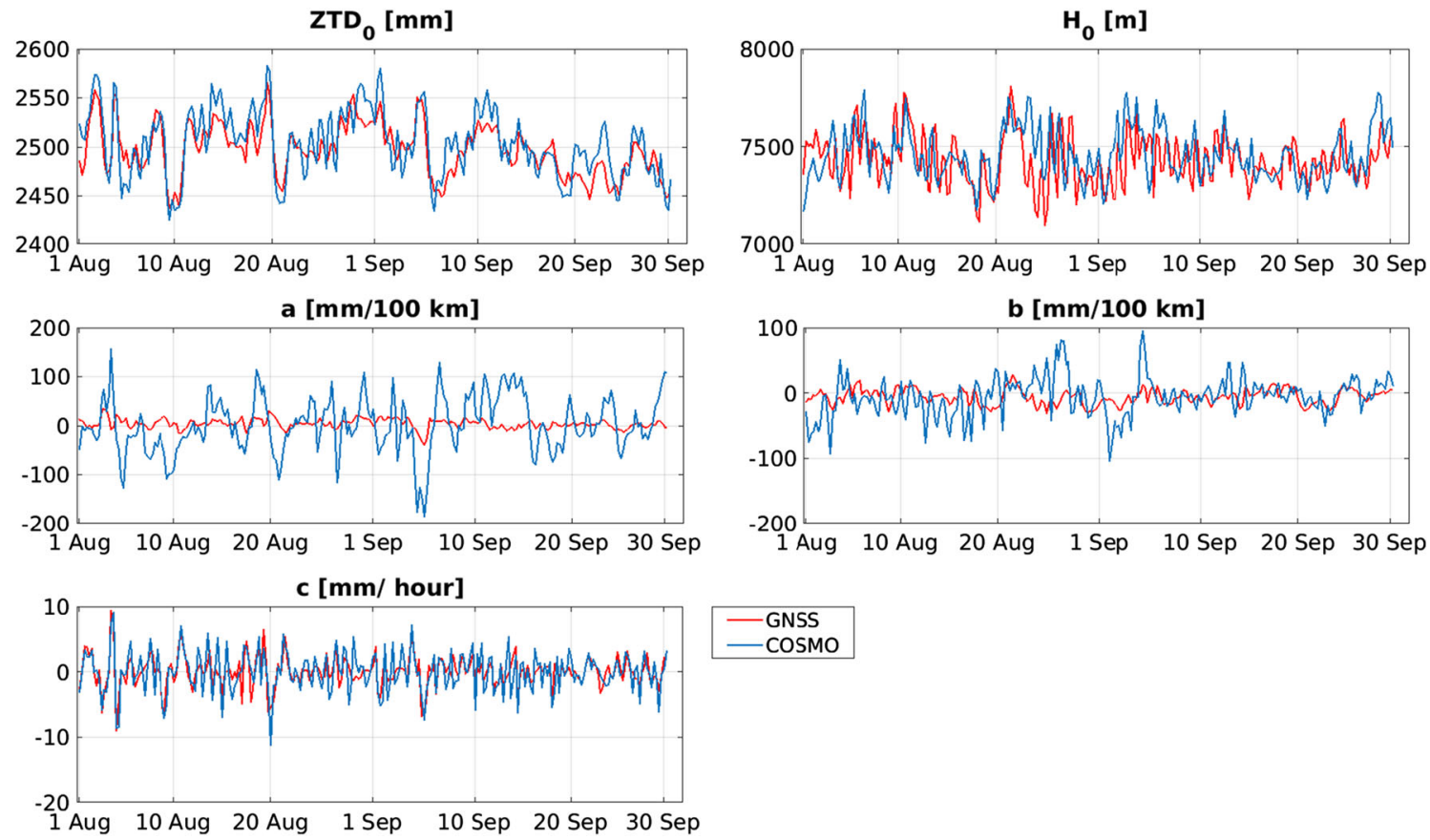

Fig. 4 Deterministic coefficients estimated in the least-squares sense for station KREB for each time batch

for each time batch. These estimated parameters allow recreating the deterministic part of ZTD from Eq. 6 at any point and time. To give an idea about the magnitude of the collocation coefficients, we present them in Fig. 4 for COSMO-1and GNSS-based models for a sample station KREB. For the COSMO-based model, for computational reasons, the coefficients are calculated from the local surrounding (less than $10 \mathrm{~km}$ from a location of the point of interest) for each time batch.

The total refractivity can be expressed as a derivative of $Z T D$ in zenith direction. Thus, when the input is total refractivity, we apply the differential operator $D=-\frac{\partial}{\partial z}$ to the model of $Z T D$ (Eq. 6) and obtain the model of total refractivity as:

$$
\begin{aligned}
& N_{\text {tot }}(x, y, z, t)=\operatorname{DZT} D(x, y, z, t)=\frac{1}{H_{0}}[\text { ZT D } 0 \\
& \left.+a\left(x-x_{0}\right)+b\left(y-y_{0}\right)+c\left(t-t_{0}\right)\right] e^{-\frac{z-z_{0}}{H_{0}}} .
\end{aligned}
$$

The correlated stochastic part of the collocation model is assumed to be normally distributed with mean 0 and the covariance matrix $C_{s s}$. The matrix is usually derived empirically and then described by a covariance function of the distances between the measurements. The covariance function for $Z T D$ in this study is chosen as:

$$
\begin{aligned}
& C_{s s}(i, j) \\
& =\frac{\sigma_{\text {signal }}^{2}}{1+\left[\left(\frac{x_{i}-x_{j}}{\Delta x_{0}}\right)^{2}+\left(\frac{y_{i}-y_{j}}{\Delta y_{0}}\right)^{2}+\left(\frac{z_{i}-z_{j}}{\Delta z_{0}}\right)^{2}+\left(\frac{t_{i}-t_{j}}{\Delta t_{0}}\right)^{2}\right] \cdot e^{-\frac{z_{i}+z_{j}}{2 z_{0}}},},
\end{aligned}
$$

where $\sigma_{\text {signal }}^{2}$ is the a priori variance of the signal, $x_{i}, y_{i}$, $z_{i}, t_{i}$ are the projected Swiss coordinates, orthometric height and time of observation $i, x_{j}, y_{j}, z_{j}, t_{j}$ are the coordinates, height and time of observation $j, z_{0}=4 \mathrm{~km}$ is the scale height modifying the correlation lengths as a function of height, $\Delta x_{0}=50 \mathrm{~km}, \Delta y_{0}=50 \mathrm{~km}, \Delta z_{0}=1 \mathrm{~km}$, $\Delta t_{0}=1.7 \mathrm{~h}$ are the empirically determined correlation lengths of space and time. The covariance function for total refractivity is obtained by applying the differential operator $D$ into Eq. 8. For more details, please refer to Wilgan et al. (2017a) or Hurter and Maier (2013). The estimated parameters of deterministic part and signal enable the interpolation of the $Z T D$ or total refractivity values at any chosen position and time. Moreover, in the software COMEDIE, it is possible to integrate different data sources into one model, for example COSMO- 1 and GNSS data. In this case, the deterministic parameters in Eqs. 6 and 7 are estimated simultaneously from all data sources.

\section{Validation with reference data}

To validate the COMEDIE-derived models, we compare the total refractivities and ZTDs based on two data sources: COSMO-1 and GNSS with reference radiosonde measurements for total refractivity and with reference GNSS data for $Z T D$. The following comparisons are made for a two-month period of August 1-September 30, 2016. 
Fig. 5 Biases and standard deviations of the differences $N_{\text {ref }}-N_{\text {model }}$, where 'ref' is the reference radiosonde measurement and 'model' is based on either COSMO-1 or GNSS. The statistics are averaged over the period of August 1-September 30, 2016. The ticks of the y-axis represent every second radiosonde height level

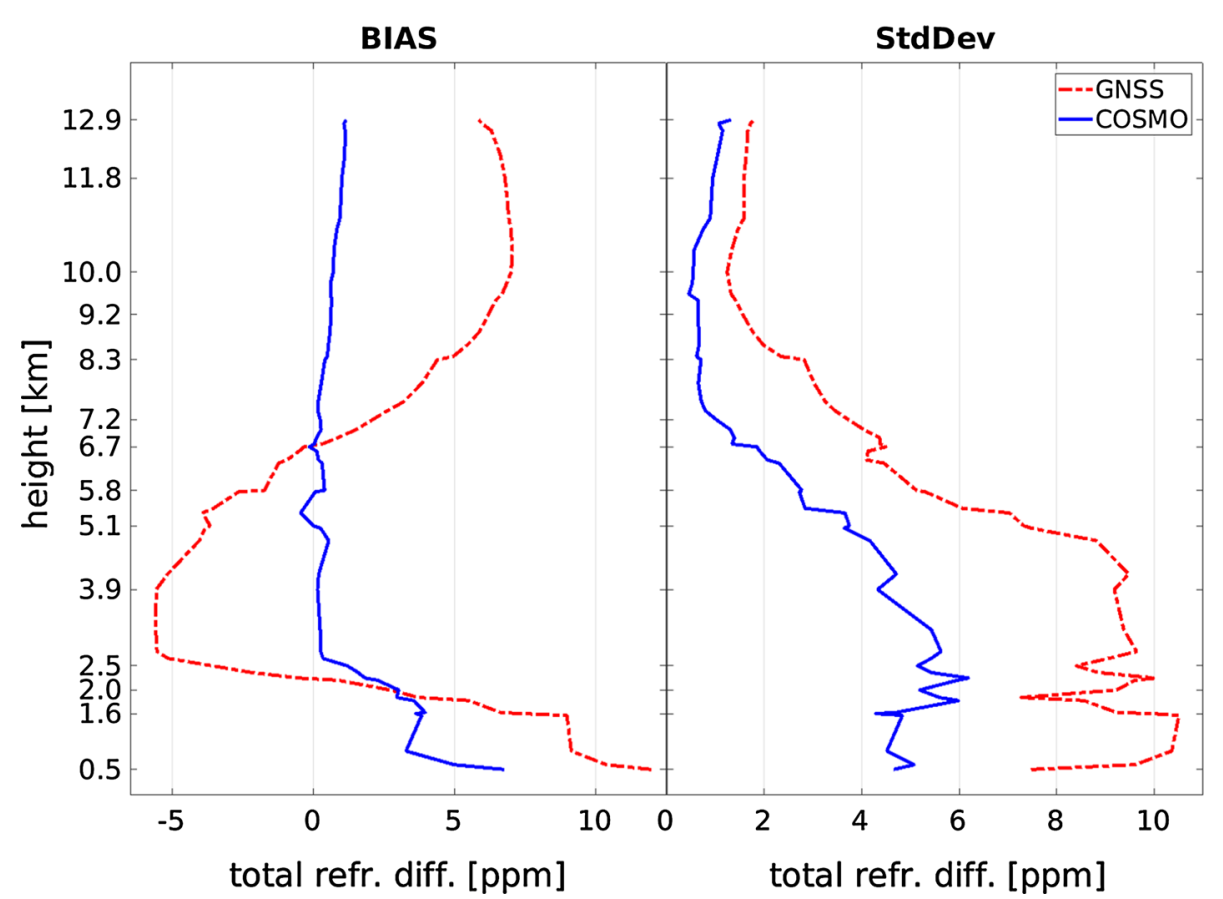

\subsection{Total refractivity comparisons with radiosonde}

Firstly, we compare the COMEDIE-derived total refractivities with radiosonde measurements in Payerne, which is the only permanently operating aerological station in Switzerland. This radiosonde station is not located in the alpine region (Fig. 2, top, yellow circle); nonetheless, we perform the comparisons to evaluate the models at different altitudes. The radiosonde is a 'weather balloon' equipped with meteorological sensors that ascends through the atmosphere and measures the values of meteorological parameters, i.e., air pressure, temperature, water vapor or wind parameters at different heights. We calculate the values of total refractivity from radiosonde measurements for every level according to Eq. 1. We download the radiosonde data from the US National Oceanic and Atmospheric Administration (NOAA) Earth System Research Laboratory Web site. ${ }^{6}$ Figure 5 shows the average biases and standard deviations of residuals $N_{\text {ref }}-N_{\text {model }}$, where 'ref' is the reference radiosonde measurement and 'model' is either COSMO-1 or GNSS based. The total refractivity is compared at all height levels of the radiosonde to assess the vertical structure of the COMEDIEderived models.

For the COSMO-based model, there is a very good agreement with the aerological measurements at every level, with biases averaged from all epochs of $6.7 \mathrm{ppm}$ at the ground level, decreasing to almost 0 at $12 \mathrm{~km}$. The standard deviations are equal to $4.6 \mathrm{ppm}$ at the ground level, decreasing to $0.7 \mathrm{ppm}$ at $12 \mathrm{~km}$. The average bias from all levels is equal to

\footnotetext{
${ }^{6}$ www.esrl.noaa.gov.
}

$1.1 \mathrm{ppm}$, which is $0.6 \%$ of a total average value of refractivity along a vertical profile with standard deviation of $2.6 \mathrm{ppm}$ $(1.6 \%)$. However, the radiosonde data are assimilated into COSMO-1 model; thus, the high correlation between NWP and radiosonde data is expected. For the GNSS-based model, there is also a good agreement with the reference data considering that we reconstruct the whole profile of refractivity using only the ZTD values from ground-based measurements. The average bias at the ground level is equal to $11.9 \mathrm{ppm}$, which decreases to $-5 \mathrm{ppm}$ at $2.5 \mathrm{~km}$ and turns back to a positive value of $3.5 \mathrm{ppm}$ at $12 \mathrm{~km}$. The bias averaged from all levels is equal to $2.6 \mathrm{ppm}(1.6 \%)$ with standard deviation of $5.1 \mathrm{ppm}(3.1 \%)$. The 'S'-like shape of the GNSS bias plot has already been seen in different previous investigations (Wilgan et al. 2017a; Möller 2017; Hurter 2014; Hurter and Maier 2013).

In the previous investigations, the COMEDIE-derived refractivity values from different data sets were compared with the radiosonde profiles in Payerne. The data set of the highest accuracy was the combination of ground-based meteorological measurements with GNSS data. Hurter and Maier (2013) compared the wet refractivity and Wilgan et al. (2017a) the total refractivity profiles calculated from three years of data (2009 - 2011). For the wet refractivity, the root-mean-square error varied between 4 and $7 \mathrm{ppm}$ with an average of around $5 \mathrm{ppm}$, while for the total refractivity the biases varied between -7 and $3 \mathrm{ppm}$ with a standard deviation of $6 \mathrm{ppm}$ averaged from all the levels. However, all of the previous comparisons were performed only up to the height of $4 \mathrm{~km}$ amsl. As shown in Fig. 5, the differences are the largest in the lower troposphere. In our study, the statistics 

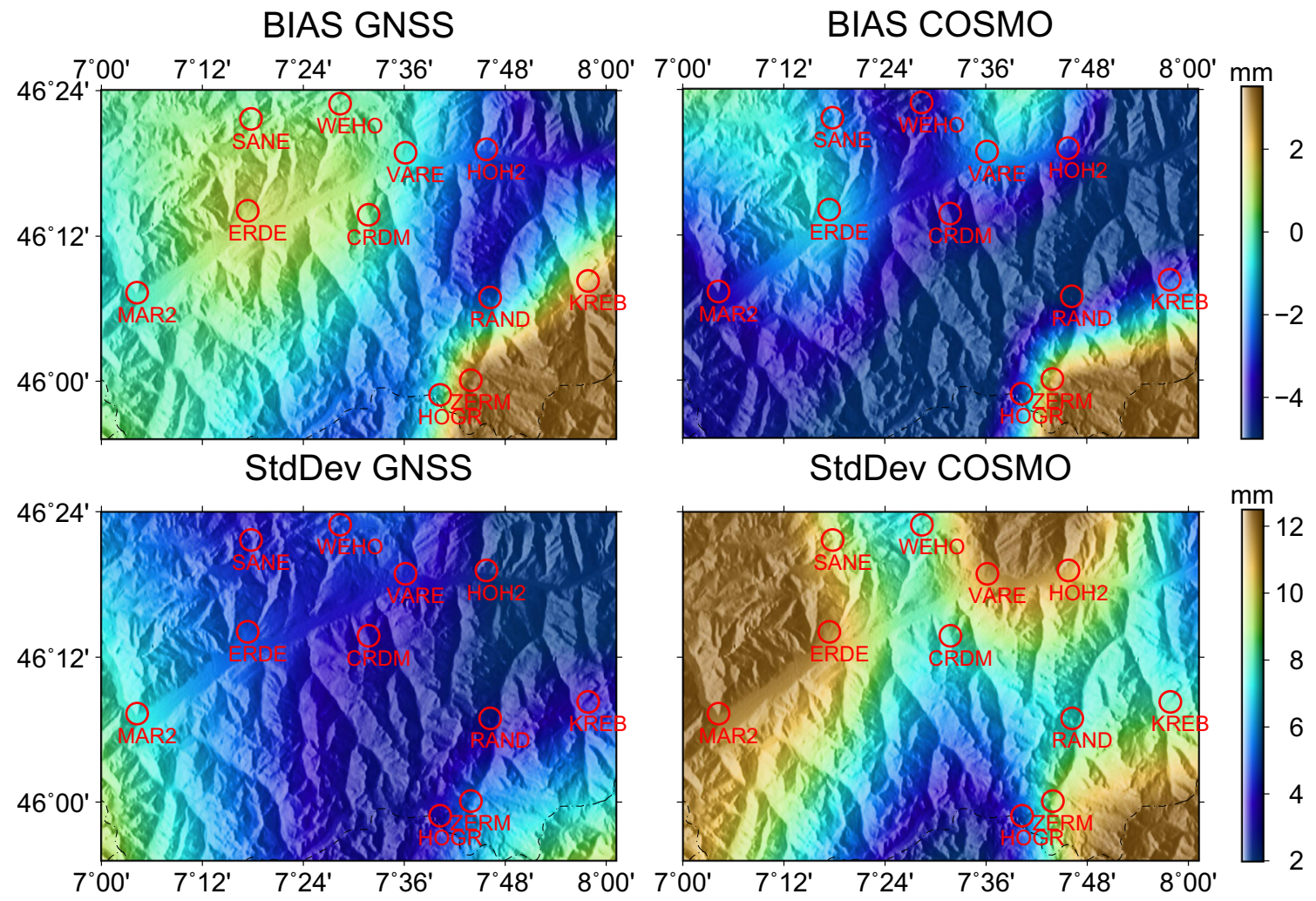

Fig. 6 Average biases and standard deviations of residuals $Z T D_{\text {ref }}-Z T D_{\text {model }}$, where 'model' is either based on GNSS or COSMO-1 data and 'ref' is the reference GNSS, interpolated over the entire area of Valais. The statistics are averaged over the period of August 1-September 30, 2016

for residuals are calculated for all of the radiosonde heights, up to approximately $13 \mathrm{~km}$. If we restrict our comparisons only up to a height of $4 \mathrm{~km}$, the average bias \pm standard deviation equals $1.8 \mathrm{ppm} \pm 4.9 \mathrm{ppm}$ for COSMO-based model and $-1.6 \mathrm{ppm} \pm 8.8 \mathrm{ppm}$ for GNSS-based model. Thus, in this study, the average statistics from the COSMO-based model are similar or slightly better than those obtained using the best combination of data sources in the previous investigations. We must also keep in mind that we compare data from two different periods. In this study, we use only two summer months, where the variability of the refractivity is higher compared to the whole year. Thus, we can conclude that this current configuration gives better results than the previous studies that used lower resolution data.

\subsection{ZTDs comparisons with reference GNSS data}

This study focuses on the tropospheric models for the alpine area. Thus, in the first step, we validate the ZT D models for 11 stations located in Valais as shown in Fig. 2, bottom plot. We compare the COSMO-1- and GNSS-based models with the reference GNSS data. In case of the GNSS-based model, we make a cross-validation; i.e., each GNSS station acts, respectively, as a reference and the GNSS measurements from this station are excluded from the collocation procedure.
Even though the reference GNSS station is not included in the model, they both are derived from GNSS data; thus, they share the same processing errors.

Figure 6 shows the biases and standard deviations of residuals $Z T D_{\text {ref }}-Z T D_{\text {model }}$, where 'ref' is the reference permanent GNSS station and 'model' is either COSMO-1 or GNSS based. For graphical purposes, we interpolate the values calculated at the stations (red circles) using the bi-cubic interpolation in Generic Mapping Tools (GMT) for the whole area of Valais to give an impression about the range of the values. The plots are superimposed with ASTER GDEM. ${ }^{7}$ Figure 7 gives the exact values of biases and their standard deviations for 11 stations in Valais.

The best agreement is achieved for the GNSS-based model, with a bias of $0.2 \mathrm{~mm}$ averaged from all stations and an average standard deviation of $4.3 \mathrm{~mm}$. The biases for most of the stations are very close to zero and are mainly positive. Two stations in the Matter Valley: KREB and ZERM have the largest biases on the order of 2-3 $\mathrm{mm}$. For another two stations, $\mathrm{HOH} 2$ and RAND, the biases are negative with the values of about $-2 \mathrm{~mm}$. The standard deviations are mostly at an uniform level of around $4 \mathrm{~mm}$. The largest value of $7.4 \mathrm{~mm}$ is for the station MAR2, which is located fur-

\footnotetext{
${ }^{7}$ https://asterweb.jpl.nasa.gov/gdem.asp.
} 


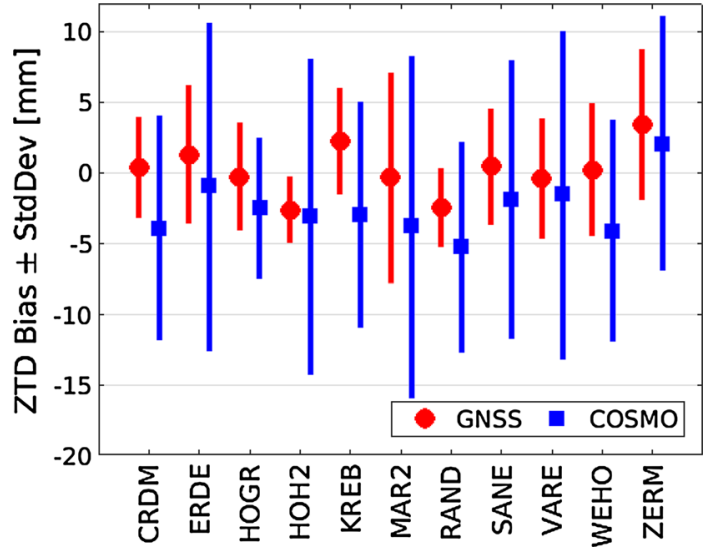

Fig. 7 Average biases \pm standard deviations of the residuals $Z T D_{\text {ref }}-$ $Z T D_{\text {model }}$ for GNSS- and COSMO-based models for 11 stations in Valais. The statistics are averaged over the period of August 1September 30, 2016

ther away to the west from the rest of the stations. For the COSMO-based model, the average bias of residuals equals $-2.5 \mathrm{~mm}$ with the standard deviation of $9.2 \mathrm{~mm}$. The biases for COSMO-derived model are mostly negative; thus, the model overestimates the $Z T D$ values. The standard deviations are larger in the north of Valais, with values of around $10-12 \mathrm{~mm}$ and smaller in the south, with values of around $8 \mathrm{~mm}$. The station MAR2, located in the west, has again the largest standard deviation of $12.2 \mathrm{~mm}$. The GNSS data are not assimilated into COSMO-1 model; thus, the comparisons are independent.

In our previous studies, we compared the COMEDIEderived ZT Ds models for Poland (Wilgan et al. 2017a). The results were much worse than the ones obtained in this study. For Poland, the standard deviation of the NWP-based model averaged from ten evenly distributed stations equaled $31.1 \mathrm{~mm}$ and for the GNSS-based model $17.2 \mathrm{~mm}$. The biases for those models were at a level of a few $\mathrm{mm}$; thus, the results in this study are mainly better in terms of standard deviations, which can be interpreted as precision of the models. The horizontal resolution of NWP model and the GNSS network in this study is much higher than it was for the Polish study. Moreover, the topography is different, because Poland is located mostly on lowlands leading to a small variability of the station heights. For these reasons, the models for Valais may be performing much better.

\section{Matter Valley case study}

We calculate very high-resolution troposphere models for Matter Valley to analyze the performance of the models from different data sources: COSMO-1, GNSS and X-Sense on a geographically limited mountainous area. We calculate the models also from the low-cost X-Sense stations to evaluate the accuracy of these stations and the feasibility of using them in situations where no geodetic receivers are available.

\subsection{Calculation of the high-resolution models}

The models are calculated for the $7 \mathrm{~km} \times 7 \mathrm{~km}$ area that embraces all of the locations of X-Sense stations and for the heights of $2 \mathrm{~m}$ Digital Elevation Model (DEM2) of swisstopo. For computational reasons, we re-sample to every tenth point, resulting in models calculated with $20 \mathrm{~m}$ resolution. In the future, the models can be calculated for the locations of InSAR pixels. We present these high-resolution models to examine the feasibility of calculating models of such high resolution from much coarser data. Figure 8 presents the models calculated for one particular date of August 20, 2016, 12:00 UTC from three different data sources. On the plots, there are also indicated: 1) the location of GNSS station RAND (left), the only station that is located within the selected area, but the GNSS-based model is calculated also from the surrounding GNSS stations, 2) the horizontal COSMO-1 grid points within the selected area (middle) and 3) the locations of all X-Sense low-cost GPS stations (right). The 3D location of RAND and X-Sense stations as well as the topography of the area are shown in Fig. 3.

As shown in Fig. 8, all models are clearly height dependent. The highest $Z T D$ values are obtained for the points located in the valley. The lowest $Z T D$ values are for the points located in the highest mountain slopes. However, in this scale, it is difficult to distinguish between the values of specific models. Thus, we calculate the differences between these three models. Figure 9 presents the biases and standard deviations of the differences between the models depicted in Fig. 8, but averaged from the whole two-month period.

The COSMO-1- and GNSS-based models are more consistent with each other than these models and X-Sense-based model. However, there are still some discrepancies between COSMO-1- and GNSS-based models in the order of few $\mathrm{mm}$. The biases vary from -4 to $2 \mathrm{~mm}$, and the standard deviations are at a level of $6 \mathrm{~mm}$ on the slopes and $9 \mathrm{~mm}$ in the valley. The X-Sense-based models agree less with the other models, especially in the valley or in the southern parts of the area. This fact is not surprising, as there are not many X-Sense stations in these areas. However, even in the northeast part of the area, where the main cluster of X-Sense stations is located, there is a bias of $-5 \mathrm{~mm}$ between X-Sense- and GNSS-based models. This may indicate a systematic error between these data sources at higher altitudes. To investigate it further, Table 1 shows the average biases and standard deviations over the entire $7 \mathrm{~km} \times 7 \mathrm{~km}$ area and also a selected $2 \mathrm{~km} \times 4 \mathrm{~km}$ area covering the main cluster of $\mathrm{X}$-Sense stations. In terms of average standard deviations between particular data sources, the two areas are similar, but the biases between GNSS and 

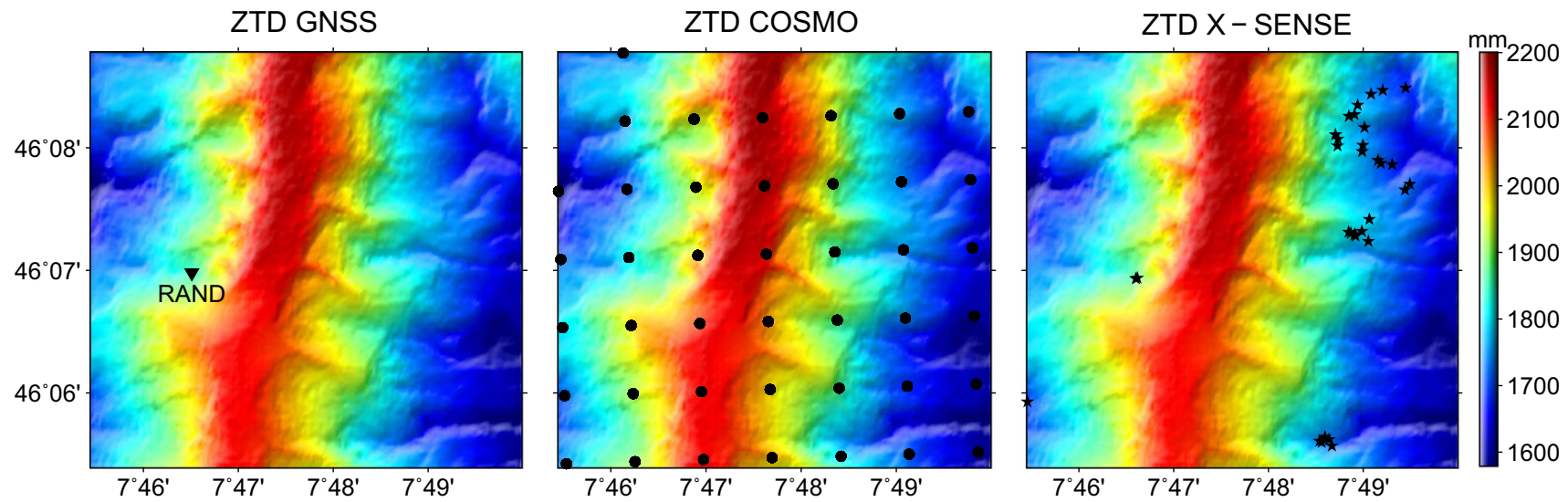

Fig. 8 ZT D models for Matter Valley calculated from three data sources: GNSS, COSMO-1 and X-Sense for a sample date of August 20, 2016, 12:00 UTC. Markers denote the locations of stations/grid points for the particular data source

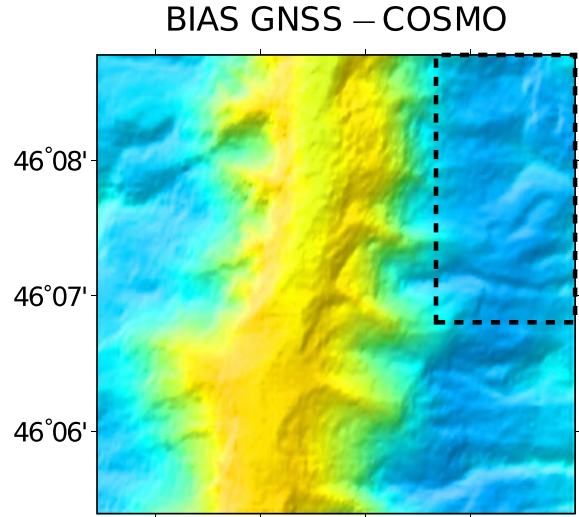

StdDev GNSS -COSMO

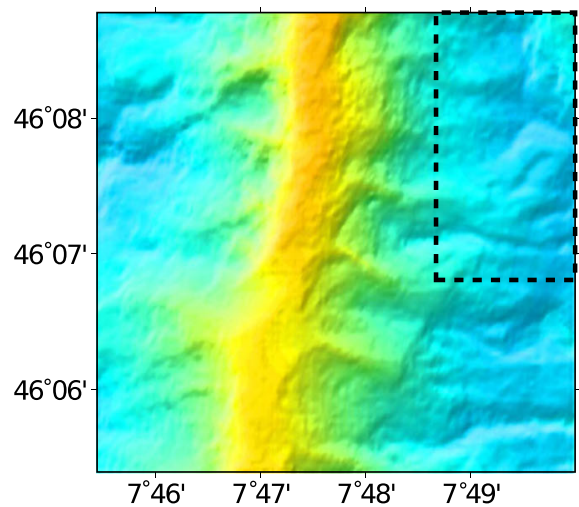

BIAS GNSS - X-SENSE

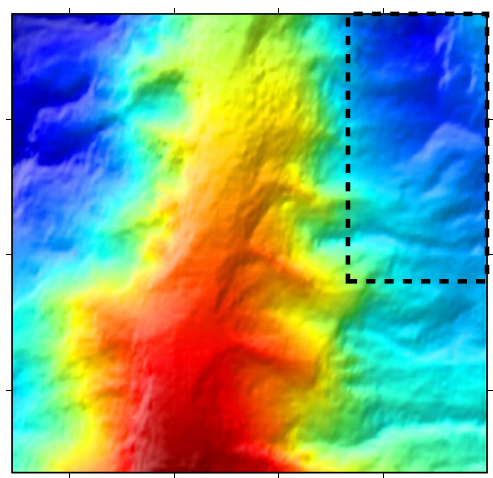

StdDev GNSS -X-SENSE

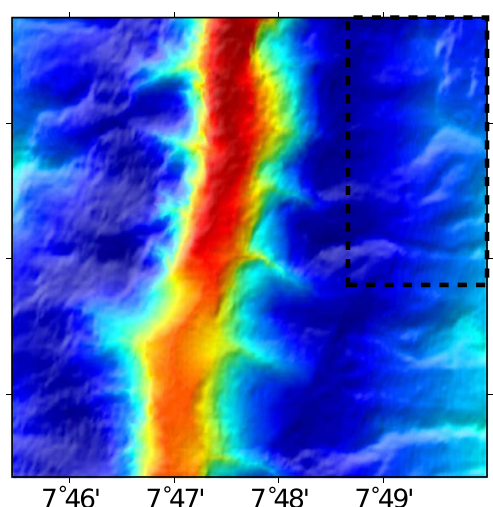

BIAS COSMO - X-SENSE
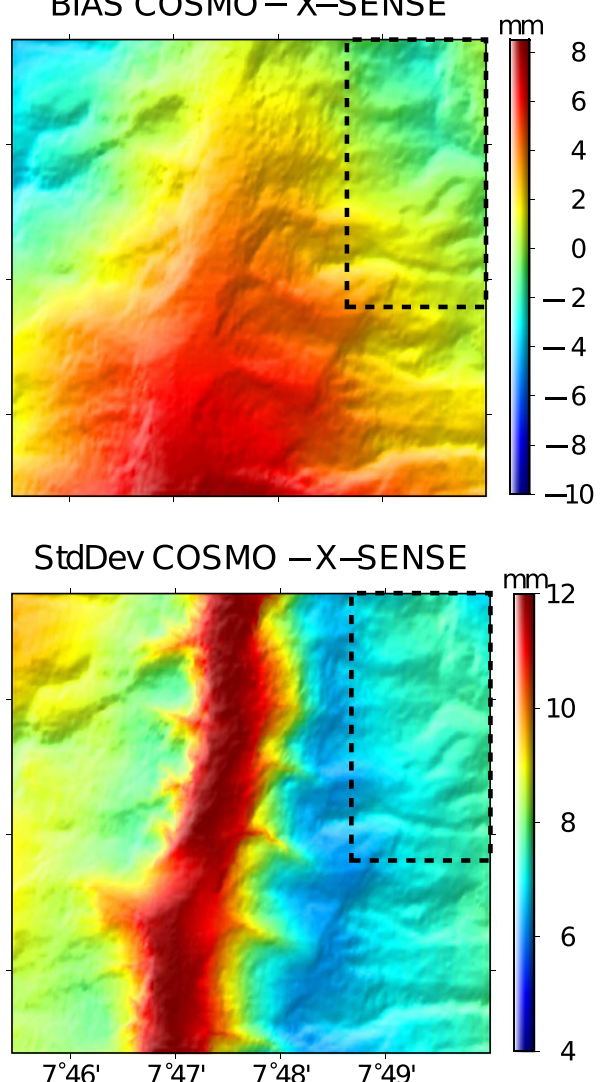

Fig. 9 Statistics of the differences between models from three data sources: GNSS, COSMO-1 and X-Sense; the statistics are averaged over the period of August 1-September 30, 2016. The dashed rectangles indicate a selected $2 \mathrm{~km} \times 4 \mathrm{~km}$ area of the main cluster of X-Sense stations

COSMO-1 and between GNSS and X-Sense are larger for the smaller area, while the bias between COSMO-1 and XSense is reduced for the smaller area. We can conclude that in the high altitudes, the X-Sense- and COSMO-based models are more coherent, because there are many X-Sense stations as well as COSMO-1 points, while the X-Sense- and GNSS- based models are more divergent, because there is just a little information from GNSS stations.

\subsection{Accuracy assessment of the models}

The calculation of the differences between models does not directly indicate which data source is of the highest accuracy 
Table 1 Cross-comparison of the models from three data sources: GNSS, COSMO-1 and X-Sense

\begin{tabular}{llllll}
\hline & \multicolumn{2}{l}{$7 \mathrm{~km} \times 7 \mathrm{~km}$} & & & $2 \mathrm{~km} \times 4 \mathrm{~km}$ \\
\cline { 2 - 3 } \cline { 5 - 6 } & Bias $(\mathrm{mm})$ & $\mathrm{SD}(\mathrm{mm})$ & & Bias $(\mathrm{mm})$ & SD $(\mathrm{mm})$ \\
\hline GNSS - COSMO & -2.9 & 7.6 & & -5.0 & 6.8 \\
GNSS - X-SENSE & -0.9 & 6.1 & & -5.1 & 5.2 \\
COSMO - X-SENSE & -2.0 & 9.7 & & -0.1 & 8.5 \\
\hline
\end{tabular}

The biases and standard deviations of the differences between models are averaged over the entire area, either $7 \mathrm{~km} \times 7 \mathrm{~km}$ or $2 \mathrm{~km} \times 4 \mathrm{~km}$ and over a period of August 1-September 30,2016

\section{RAND}

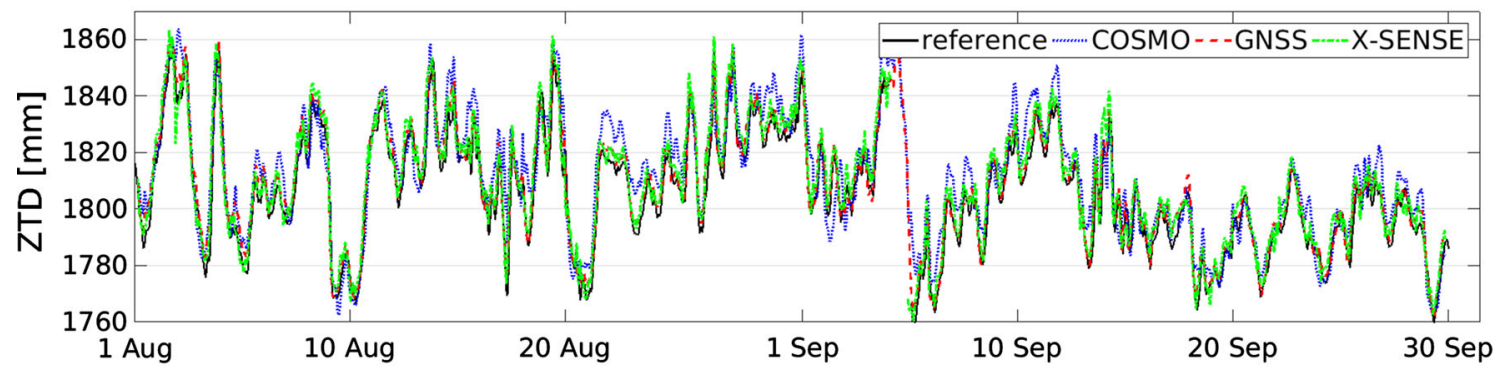

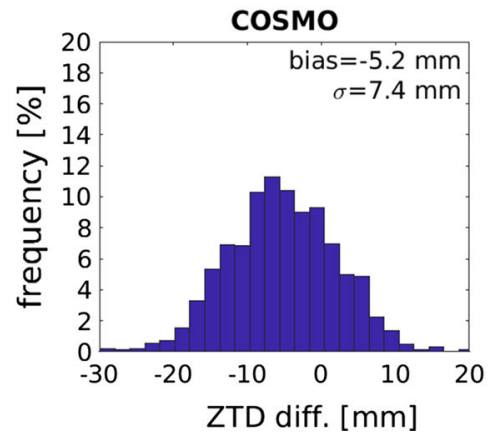

Fig. 10 Validation at station Randa (RAND). The upper plot shows the reference GNSS ZT D and three COMEDIE-based ZT D models from COSMO-1, GNSS and X-Sense data. The lower plots present the his-
GNSS

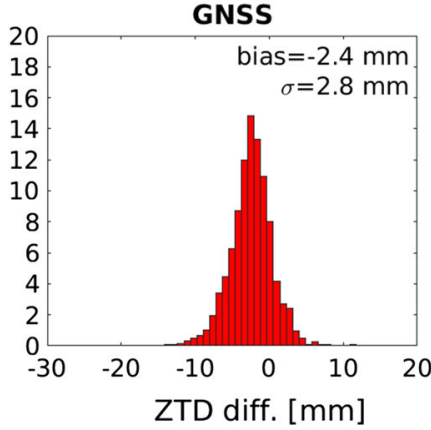

X-SENSE

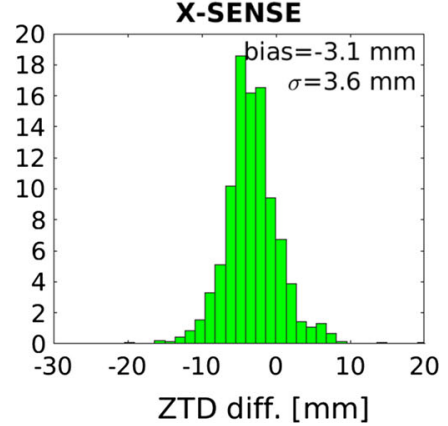

tograms of differences $Z T D_{\text {ref }}-Z T D_{\text {model }}$, where 'model' is either COSMO-1, GNSS or X-Sense based

or would be the most suitable to build a high-resolution model for InSAR corrections. Thus, we validate the particular data sources at three GNSS stations: Randa (RAND), which is located in the center of the selected area at a height of $2415 \mathrm{~m}$ and for two other stations nearby: Zermatt (ZERM), located along the same valley, around $13 \mathrm{~km}$ from station RAND at a height of $1879 \mathrm{~m}$ and Kreuzboden (KREB), located in the neighboring valley, around $15 \mathrm{~km}$ from RAND at a height of $2412 \mathrm{~m}$. In the neighborhood, there is one more station: Hörnligrat (HOGR), but during the chosen period, this station was not working continuously. Other GNSS stations are too far away from the study area to use the information from $\mathrm{X}$-Sense stations. Figures 10,11 and 12 show the assessment of COMEDIE-derived ZT Ds from three different data sources for RAND, KREB and ZERM, respectively. Similar to the processing in Sect. 4.2, the GNSS measurements at the station for which we interpolate the values are excluded from the collocation procedure, to make the comparisons with the reference GNSS data independent. Table 2 gives the biases and standard deviations for all three models w.r.t. the reference GNSS data.

For station RAND, the best agreement is achieved for the models based on GNSS and X-Sense. Both models behave very similarly and differ from each other by less than $1 \mathrm{~mm}$. The average bias \pm standard deviation is equal to $-2.4 \pm 2.8 \mathrm{~mm}$ and $-3.1 \pm 3.6 \mathrm{~mm}$ for the GNSS- and XSense-based models, respectively. The X-Sense ZT Ds are relative to GNSS ZT Ds from station RAND; thus, unfortunately, the comparison for X-Sense-based model is not independent. For stations KREB and ZERM, which are not located in the selected area and are further away from the X-Sense stations, the GNSS-based models still hold the best agreement with the reference data with both biases and standard deviations at a level of few $\mathrm{mm}$. The X-Sense-based models have worse agreement than for station RAND. For $\mathrm{KREB}$, the average bias equals only $1.0 \mathrm{~mm}$, but the standard 


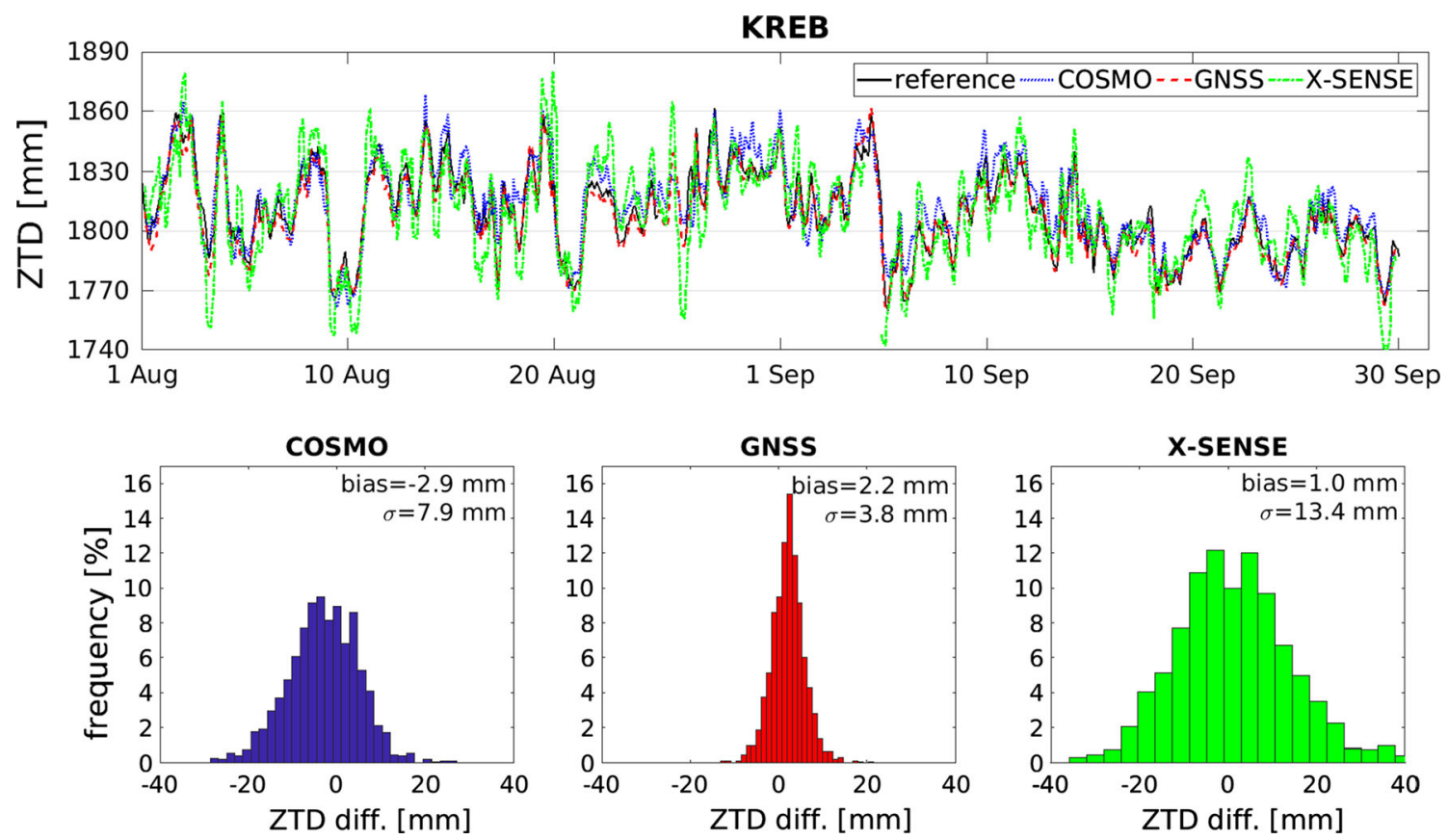

Fig. 11 Validation at station Kreuzboden (KREB). The rest of description is analogical to Fig. 10

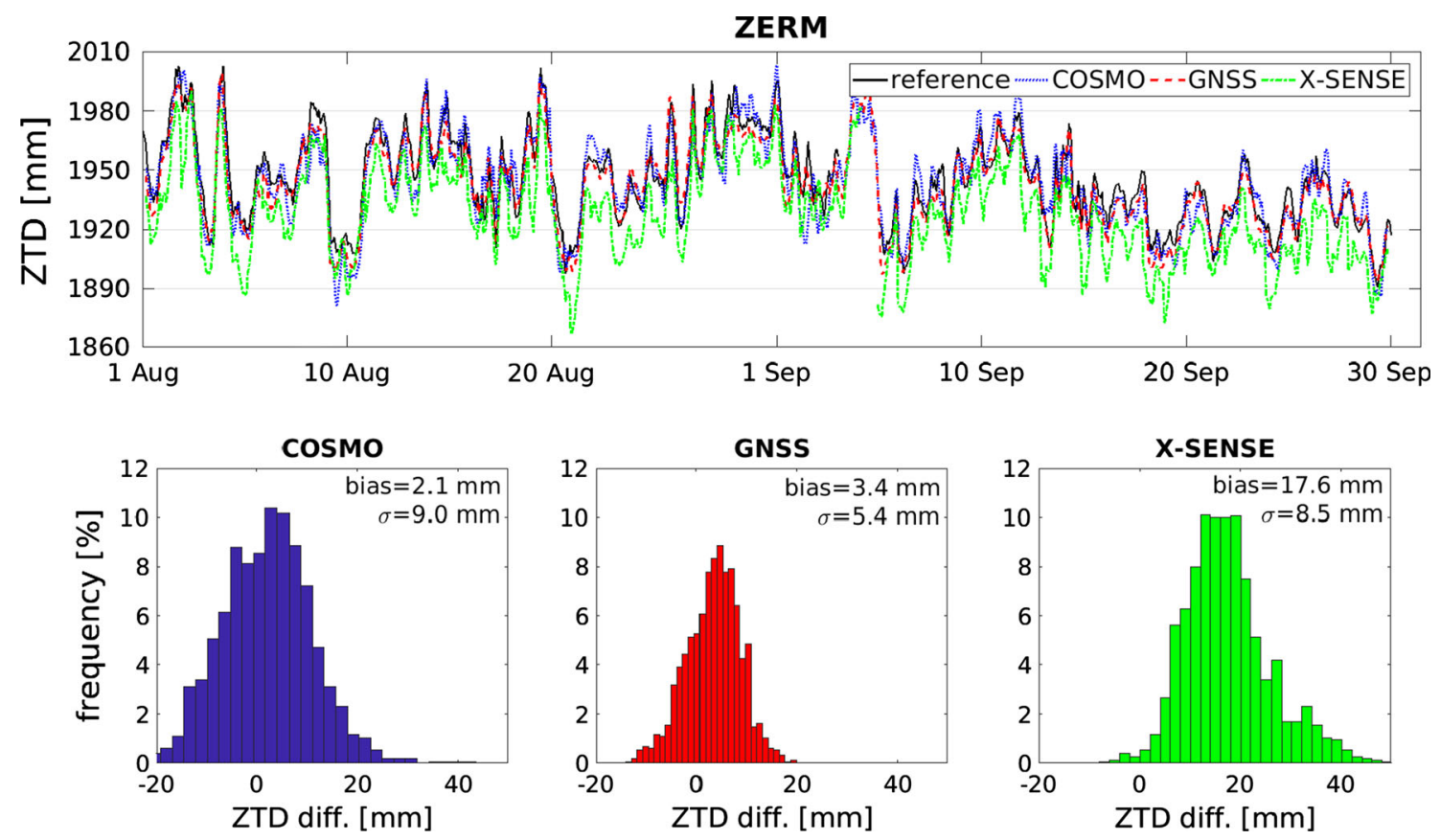

Fig. 12 Validation at station Zermatt (ZERM). The rest of description is analogical to Fig. 10

deviation equals $13.4 \mathrm{~mm}$. For ZERM, the standard deviation is smaller, about $8 \mathrm{~mm}$, but there is an offset of $17.6 \mathrm{~mm}$. The small bias for station KREB may be a consequence of a fact that KREB is located at a very similar height as RAND, while between ZERM and RAND there is almost $600 \mathrm{~m}$ of height difference. Although the results for X-Sense-based models are much worse than for the GNSS-based models, they are acceptable compared to the previous publications. One must keep in mind that these stations have L1-only receivers, but their agreement with the reference data for stations RAND and KREB is actually higher than the one obtained from 'GNSS-only' model in Wilgan et al. (2017a). For station ZERM, the offset is unfortunately much more significant. We may conclude that the X-Sense-based models perform 
Table 2 Statistics of differences $Z T D_{\text {ref }}-Z T D_{\text {model }}$ for all combinations of data sets for stations RAND, KREB and ZERM

\begin{tabular}{|c|c|c|c|c|c|c|}
\hline \multirow[t]{2}{*}{ Station } & \multicolumn{2}{|l|}{ RAND } & \multicolumn{2}{|l|}{ KREB } & \multicolumn{2}{|l|}{ ZERM } \\
\hline & $\operatorname{Bias}(\mathrm{mm})$ & $\mathrm{SD}(\mathrm{mm})$ & Bias (mm) & $\mathrm{SD}(\mathrm{mm})$ & Bias (mm) & $\mathrm{SD}(\mathrm{mm})$ \\
\hline COSMO & -5.2 & 7.4 & -2.9 & 7.9 & 2.1 & 9.0 \\
\hline GNSS & -2.4 & 2.8 & 2.2 & 3.8 & 3.4 & 5.4 \\
\hline X-SENSE & -3.1 & 3.6 & 1.0 & 13.4 & 17.6 & 8.5 \\
\hline COSMO/GNSS & -5.2 & 7.4 & -2.9 & 8.0 & 1.8 & 9.2 \\
\hline COSMO/X-SENSE & -5.2 & 6.9 & -2.9 & 7.8 & 2.0 & 9.2 \\
\hline GNSS/X-SENSE & -3.6 & 2.8 & -1.8 & 4.2 & 3.4 & 5.4 \\
\hline COSMO/GNSS/X-SENSE & -5.2 & 6.9 & -2.9 & 7.8 & 1.8 & 9.3 \\
\hline X-SENSE 6 & -3.8 & 3.3 & 8.9 & 12.2 & 17.4 & 9.4 \\
\hline GNSS/X-SENSE 6 & -2.8 & 2.5 & 0.6 & 3.8 & 3.5 & 5.4 \\
\hline
\end{tabular}

Data are averaged over a period of August 1-September 30, 2016

well obviously in the area where the stations are located, but they can also be extrapolated for regions of similar topography. The COSMO-based models exhibit negative biases for stations RAND and KREB and small positive bias for station ZERM. The standard deviations are at similar level of 7-9 mm. The statistics for COSMO-1- and GNSS-based models for all of the stations in the Valais are discussed in Sect. 4.2 .

\subsection{Combinations of data sources}

In the software COMEDIE, it is feasible to calculate the models based on different combinations of data sources. From the three data sources, the following combinations are possible: 'COSMO only,' 'GNSS only,' 'X-Sense only,' 'COSMO/GNSS,' 'COSMO/X-Sense,' 'GNSS/X-Sense' and 'COSMO/GNSS/X-Sense.' Figure 13 shows the histograms of the differences between the models from the four latter combinations of data sets and the reference ZT Ds for station KREB. The combinations based only on one data source are already presented in Fig. 11. Table 2 shows the statistics for residuals for three stations: RAND, KREB and ZERM for all seven possible combinations of data sources.

Combining the data sources does not effectively improve the model and its accuracy. The COSMO-1 model always dominates its combinations. If the combined set contains the COSMO-1 data, it exhibits similar accuracy as the 'COSMO only' data set. The reason for that is the uniform and dense distribution of the COSMO-1 points, which results in the highest distance-related weights in the collocation procedure over the entire area. In the combination 'GNSS/X-Sense,' the GNSS data have larger influence on the data set, especially for stations KREB and ZERM, which are further away from the study area. For station RAND, both 'GNSS only' and 'X-Sense only' data sets exhibit very high accuracy; thus, the combined set also has very high accuracy. For the combined
'GNSS/X-Sense' set, the standard deviation is the same as for the 'GNSS only' set, but the absolute bias is slightly larger. For KREB and ZERM, the X-Sense stations have smaller weights in the collocation procedure, as the distances from these stations increase. Thus, the 'GNSS/X-Sense' combination is mostly influenced by the GNSS data, but its accuracy is still slightly worse than for the 'GNSS only' set. The possible reason for that may be taking too many X-Sense stations over a limited area. To test this assumption, we take only six $\mathrm{X}$-Sense stations more evenly distributed across the whole scene; for example, we take only two stations at different heights from the main batch. Two last rows of Table 2 show the statistics for data sets ' $\mathrm{X}$-Sense 6' and 'GNSS/X-Sense 6.' For the 'X-Sense 6' set, there is of course no improvement w.r.t. the data set 'X-Sense only,' as we build the model from too few stations. There is even a large offset introduced for station KREB. However, for the 'GNSS/X-Sense 6,' we see a positive or neutral impact of augmenting the GNSS network only with a few X-Sense stations. For stations RAND and KREB, the errors are reduced, while for ZERM there is no impact. Reducing the number of X-Sense stations in the combination with COSMO does not bring any changes in the statistics; thus, it is not shown.

\section{Spatial variability of the models}

The validation of the empirical models is not an easy task. In the previous sections, we assessed the accuracy and precision of the obtained models w.r.t. the reference data. However, such comparisons are valid only for the locations of the stations and are limited to the quality of the reference data. In some situations, there are no reference data available. Thus, in this section, we introduce another measure of testing the high-resolution troposphere models, i.e., the spatial variability factor. To assess the spatial variability, we interpolate the 

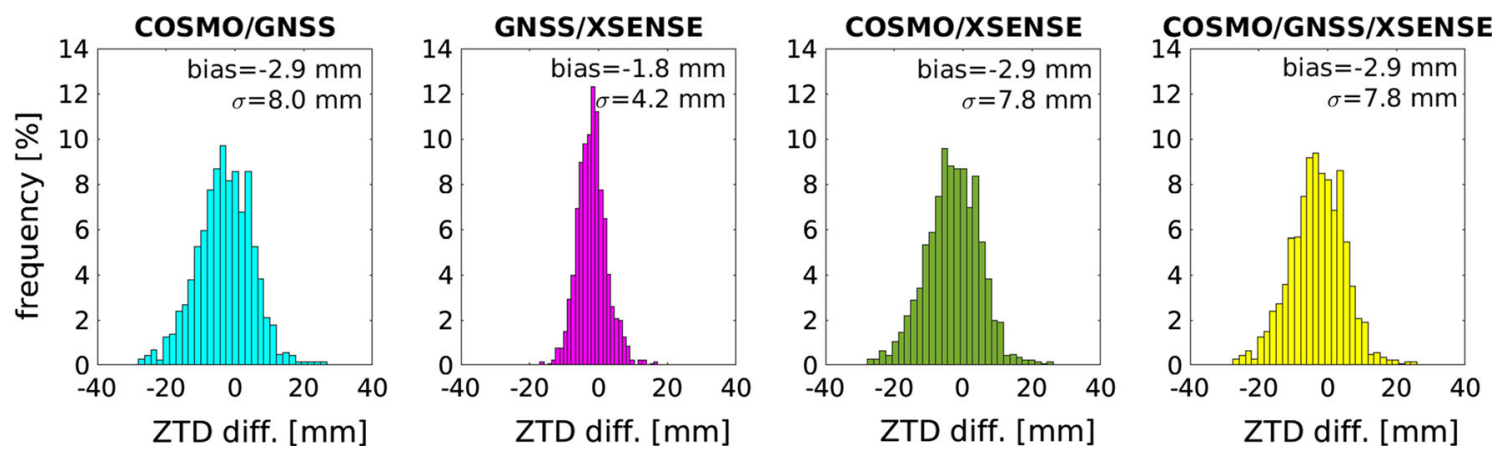

Fig. 13 Histograms of differences between the reference GNSS ZT D at station KREB and models from four combined data sets: 'COSMO/GNSS,' 'COSMO/X-Sense,' 'GNSS/X-Sense' and 'COSMO/GNSS/X-Sense'

\subsubsection{UTC H=3726 m}
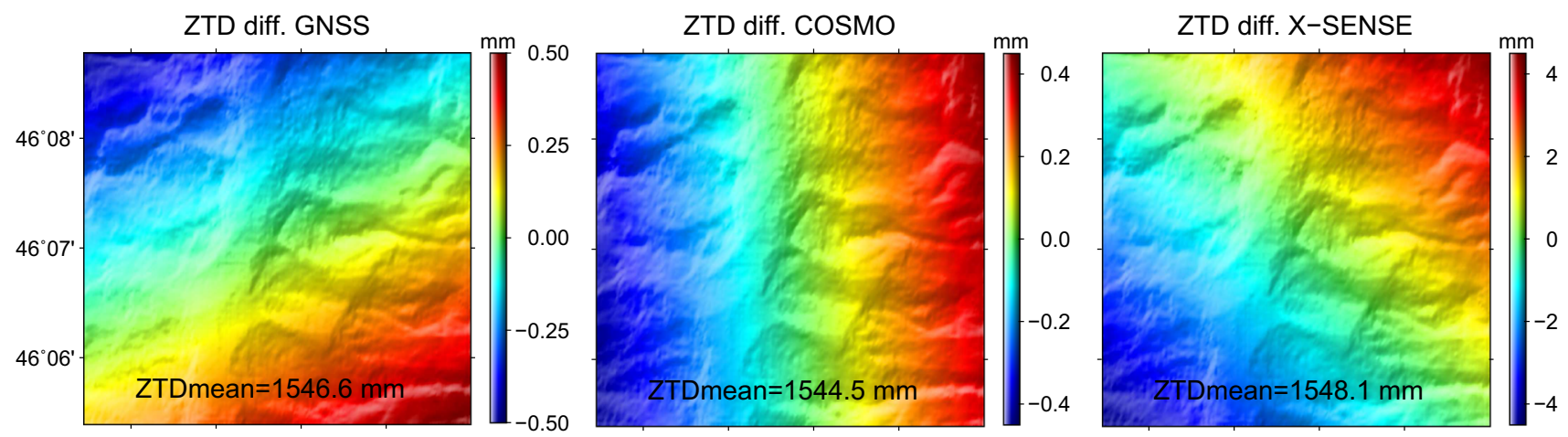

\subsubsection{UTC H=3726 m}
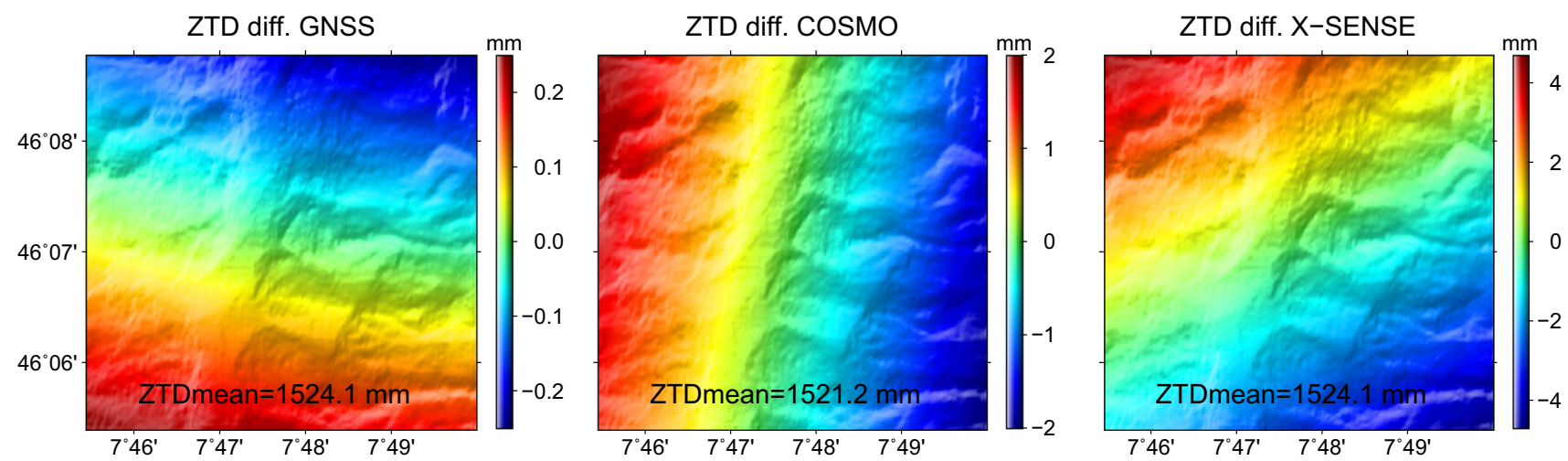

Fig. 14 Models of ZT D from three data sources: GNSS, COSMO-1 and X-Sense interpolated at equal height of $3726 \mathrm{~m}$ for two different epochs with the mean value over the whole area subtracted. The mean values are also presented in the figures

models from three data sources: COSMO-1, GNSS and XSense at equal height for all points within the study area. The chosen height of $\mathrm{H}=3726 \mathrm{~m}$ amsl is the height of the highest point in the investigated area in Matter Valley. The chosen height is the 'worst case scenario.' For lower altitudes, the variability of all models is proportionally higher. Figure 14 shows the ZT D models calculated for two different epochs: August 20, 2016, 12:00 UTC (upper row) and September 13, 2016, 12:00 UTC (lower row) with subtracted mean values over the whole area for the particular date. We subtract the mean $Z T D$ value to characterize the range of variability of the models.

The GNSS-based model is almost constant throughout the whole area. The GNSS stations have the coarsest distribution; thus, if the height factor is removed, the model does not exhibit much variability. The COSMO-based model is sometimes also almost constant as for August 20, 2016; however, there are epochs, such as September 13, 2016, where the model varies at a level of few $\mathrm{mm}$. The COSMO-1 is a local NWP model and has a very high resolution of $1.1 \mathrm{~km}$ 


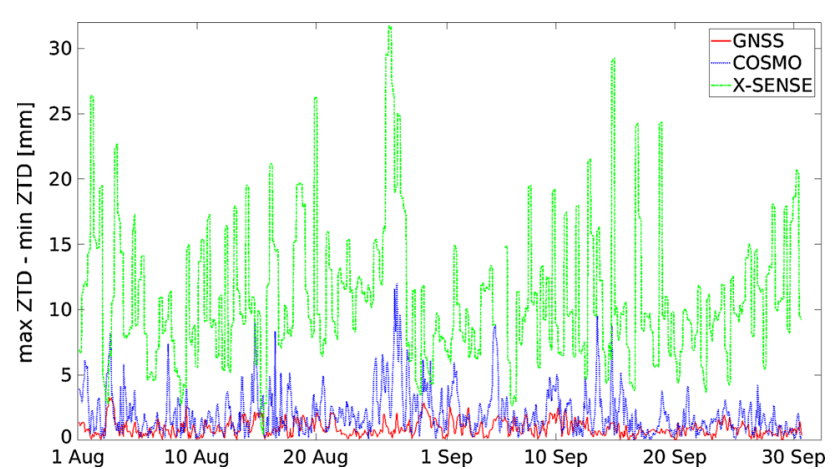

Fig. 15 Hourly differences between maximum and minimum ZTD within the investigated area at an equal height for GNSS-, COSMO-1and X-Sense-based models

Table 3 Ranges of $Z T D$ values from three data sources and for three different heights averaged over a period of August 1-September 30, 2016

\begin{tabular}{lccc}
\hline Height & $\begin{array}{l}\mathrm{H}=3726 \mathrm{~m} \\
(\mathrm{~mm})\end{array}$ & $\begin{array}{l}\mathrm{H}=2412 \mathrm{~m} \\
(\mathrm{~mm})\end{array}$ & $\begin{array}{l}\mathrm{H}=1218 \mathrm{~m} \\
(\mathrm{~mm})\end{array}$ \\
\hline GNSS & 0.9 & 1.7 & 2.0 \\
COSMO & 2.1 & 3.0 & 3.5 \\
X-SENSE & 10.9 & 12.9 & 15.2 \\
\hline
\end{tabular}

compared to other NWP models. However, the regular distribution of COSMO-1 points has a moderate influence on the $Z T D$ variability. The $\mathrm{X}$-Sense stations are located mostly in one batch in the northeast of the area. The inter-station distance within this batch is only $130 \mathrm{~m}$. This dense distribution of stations located at various heights results in a highest variability of X-Sense-based model over the entire area.

To further test the variability factor, we calculate the differences between the maximum and minimum $Z T D$ value for all of the time points from the whole $7 \mathrm{~km} \times 7 \mathrm{~km}$ area. Figure 15 shows these ranges for each epoch for three models. For GNSS-based model, the differences are very small and consistent for all of the epochs. For COSMO-based model, there are days when the range is larger, for example August 28, 2016, but in general the differences are within few $\mathrm{mm}$. For X-Sense-based models, the differences range from few $\mathrm{mm}$ to few $\mathrm{cm}$. Table 3 shows the average ranges from all three models calculated for three different height levels: highest point of the area $(H=3726 \mathrm{~m})$, the median point $(H=2412 \mathrm{~m})$ and the lowest $(H=1218 \mathrm{~m})$. For the median and the lowest points, the ranges are proportionally higher, but the order remains the same; i.e., the GNSS-based models have the lowest variability, while the $\mathrm{X}$-Sense-based models, the highest. The variability factor is a direct consequence of the distribution of the chosen input points. The denser the network, also with regard to the height distribution, the higher the variability is. While this conclusion is quite apparent, it is important to keep this factor in mind in building high-resolution tropospheric models as an addition to the accuracy assessment of particular data sources; not only the horizontal distribution, but also the height variability of the input points impacts the built tropospheric model.

\section{Summary}

In this study, we presented the total refractivity and zenith total delay models for Switzerland based on GNSS and NWP COSMO-1 data using the least-squares collocation software COMEDIE. In the first part, we validated our models against the reference radiosonde measurements for total refractivity and reference GNSS data for ZT D. The accuracy of both GNSS- and NWP-based models was much higher in comparison with our previous studies on this topic. In this study, we used a denser GNSS network and a higher resolution NWP model. Thus, we can conclude that using higher resolution input data enhances the overall accuracy of the tropospheric models. Moreover, we calculated very high-resolution ZT D models for a case study in Matter Valley. In addition to COSMO-1- and GNSS-based models, we presented a third model based on a very dense network of low-cost GPS L1only permanent stations (X-Sense). The side goal of this study was to assess whether such network can contribute to building tropospheric models. We estimated the $Z T D$ values from three data sources for a geographically limited area of $7 \mathrm{~km} \times 7 \mathrm{~km}$ with $20 \mathrm{~m}$ resolution. We validated these models against three reference GNSS stations: RAND, which is located within the area of interest, KREB and ZERM, which are located 15 and $13 \mathrm{~km}$ away from station RAND, respectively. For station RAND, both X-Sense- and GNSS-based models had similar best agreement with the reference data on a level of few mm. For KREB, which is located at similar height as RAND, the bias was small (only $1 \mathrm{~mm}$ ), but the standard deviation was higher $(13.4 \mathrm{~mm})$. This is a worse agreement than for COSMO- or GNSS-based models, but it is still better than for geodetic permanent stations from our previous studies. For ZERM, which is located at altitude almost $600 \mathrm{~m}$ lower than RAND, the bias was larger $(17.6 \mathrm{~mm})$, but the standard deviation was smaller $(8.5 \mathrm{~mm})$. Thus, we can conclude that the low-cost L1-only stations can contribute to building tropospheric models, constrained to a local area or areas of similar height. It is worth to note that setting up a network of low-cost stations in difficult terrain such as in the high mountains can be also beneficial for obtaining tropospheric models. Our low-cost network was also not uniformly distributed. Having more evenly distributed stations could probably also contribute to having better accuracy of such models. Furthermore, we tested whether combining the data sources can positively influence the tropospheric models. Unfortunately, combining the data sources did not improve the overall accuracy. However, in case of 'GNSS/X- 
Sense' data set, when we took only a few evenly distributed low-cost stations, the accuracy was slightly better than for the previously best 'GNSS only' set. In addition to comparing the models to the reference data, we validated them by introducing a variability factor. The variability of particular models depends strongly on the resolution of the input data. Thus, it is the lowest for GNSS-based and the highest for X-Sense-based models. The high variability of X-Sense data may be an important factor for constructing the highresolution troposphere models. Combining the data sources of the highest accuracy, such as GNSS, with the high-varying data, such as X-Sense, can profit in having both high accuracy and variability for future applications.

Acknowledgements This work was conducted within a framework of a Swiss Federal Office of Environment project 'Geodetic developments for geohazard monitoring' (14.0022.PJ). K. Wilgan was supported by the Foundation for Polish Science (FNP, START 2017 scholarship). We thank MeteoSwiss for providing the COSMO-1 model, Elmar Brockmann from swisstopo for providing AGNES/COGEAR GNSS data and Philippe Limpach for carrying out path delays calculations from XSense data. The X-Sense project is funded by 'nano-tera' Swiss National Foundation Program.

Open Access This article is distributed under the terms of the Creative Commons Attribution 4.0 International License (http://creativecomm ons.org/licenses/by/4.0/), which permits unrestricted use, distribution, and reproduction in any medium, provided you give appropriate credit to the original author(s) and the source, provide a link to the Creative Commons license, and indicate if changes were made.

\section{References}

Alshawaf F, Balidakis K, Dick G, Heise S, Wickert J (2017) Estimating trends in atmospheric water vapor and temperature time series over Germany. Atmos Meas Tech 10(9):3117

Bekaert D, Hooper A, Wright T (2015a) A spatially variable power law tropospheric correction technique for InSAR data. JGR Solid earth 120(2):1345-1356

Bekaert D, Walters R, Wright T, Hooper A, Parker D (2015b) Statistical comparison of InSAR tropospheric correction techniques. Remote Sens Environ 170:40-47

Bennitt GV, Jupp A (2012) Operational assimilation of GPS zenith total delay observations into the Met Office numerical weather prediction models. Mon Weather Rev 140(8):2706-2719

Beutel J, Buchli B, Ferrari F, Keller M, Zimmerling M (2011) XSENSE: sensing in extreme environments. In: Design, automation $\&$ test in Europe (DATE). IEEE, pp 1-6

Boniface K, Ducrocq V, Jaubert G, Yan X, Brousseau P, Masson F, Champollion C, Chéry J, Doerflinger E (2009) Impact of highresolution data assimilation of GPS zenith delay on Mediterranean heavy rainfall forecasting. Ann Geophys 27:2739-2753

Dach R, Lutz S, , Walser P, Fridez P (2015) Bernese GNSS Software Version 5.2. Astronomical Institute, University of Bern

Delaloye R, Lambiel C, Lugon R, Raetzo H, Strozzi T (2007) Typical ERS InSAR signature of slope movements in a periglacial mountain environment (Swiss Alps). In: Proceedings of the ENVISAT symposium 2007 de Oliveira P, Morel L, Fund F, Legros R, Monico J, Durand S, Durand F (2017) Modeling tropospheric wet delays with dense and sparse network configurations for PPP-RTK. GPS Solut 21(1):237-250

Eckert V, Cocard M, Geiger A (1992a) COMEDIE:(Collocation of Meteorological Data for Interpretation and Estimation of Tropospheric Pathdelays) Teil I: Konzepte, Teil II: Resultate. Technical Report 194, ETH Zürich. Grauer Bericht

Eckert V, Cocard M, Geiger A (1992b) COMEDIE:(Collocation of Meteorological Data for Interpretation and Estimation of Tropospheric Pathdelays) Teil III: Software. Technical Report 195, ETH Zürich. Grauer Bericht

Essen L, Froome K (1951) The refractive indices and dielectric constants of air and its principal constituents at $24,000 \mathrm{mc} / \mathrm{s}$. Proc Phys Soc Sect B 64(10):862

Foster J, Brooks B, Cherubini T, Shacat C, Businger S, Werner C (2006) Mitigating atmospheric noise for InSAR using a high resolution weather model. Geophys Res Lett 33(16):L16304

Hobiger T, Kinoshita Y, Shimizu S, Ichikawa R, Furuya M, Kondo T, Koyama Y (2010) On the importance of accurately ray-traced troposphere corrections for Interferometric SAR data. J Geod 84(9):537-546

Hooper A, Bekaert D, Spaans K, Arıkan M (2012) Recent advances in SAR interferometry time series analysis for measuring crustal deformation. Tectonophysics 514:1-13

Hurter F (2014) GNSS meteorology in spatially dense networks. Ph.D. thesis, Eidgenössische Technische Hochschule ETH Zürich, Nr. 22005

Hurter F, Maier O (2013) Tropospheric profiles of wet refractivity and humidity from the combination of remote sensing data sets and measurements on the ground. Atmos Meas Tech 6(11):3083-3098

Kääb A, Huggel C, Fischer L, Guex S, Paul F, Roer I, Salzmann N, Schlaefli S, Schmutz K, Schneider D et al (2005) Remote sensing of glacier-and permafrost-related hazards in high mountains: an overview. Nat Hazard Earth Sys 5(4):527-554

Kinoshita Y, Furuya M, Hobiger T, Ichikawa R (2013) Are numerical weather model outputs helpful to reduce tropospheric delay signals in InSAR data? J Geod 87(3):267-277

Lambiel C, Delaloye R, Strozzi T, Lugon R, Raetzo H (2008) ERS InSAR for assessing rock glacier activity. In: Ninth international conference on permafrost, edited by: Kane, DL, Hinkel, KM, Fairbanks: University of Alaska Fairbanks, pp 1019-1024

Lateltin O, Haemmig C, Raetzo H, Bonnard C (2005) Landslide risk management in Switzerland. Landslides 2(4):313-320

Li Z, Fielding E, Cross P, Preusker R (2009) Advanced InSAR atmospheric correction: MERIS/MODIS combination and stacked water vapour models. Int J Remote Sens 30(13):3343-3363

Lu C, Li X, Zus F, Heinkelmann R, Dick G, Ge M, Wickert J, Schuh H (2017) Improving BeiDou real-time precise point positioning with numerical weather models. J Geod 91(9):1019-1029

Mateus P, Nico G, Tomé R, Catalao J, Miranda PM (2013) Experimental study on the atmospheric delay based on GPS, SAR interferometry, and numerical weather model data. IEEE Trans Geosci Remote Sens 51(1):6-11

Möller G (2017) Reconstruction of 3D wet refractivity fields in the lower atmosphere along bended GNSS signal paths. Ph.D. thesis, Technischen Universität Wien

Nico G, Tome R, Catalao J, Miranda PM (2011) On the use of the WRF model to mitigate tropospheric phase delay effects in SAR interferograms. IEEE Trans Geosci Remote Sens 49(12):4970 4976

Puysségur B, Michel R, Avouac JP (2007) Tropospheric phase delay in interferometric synthetic aperture radar estimated from meteorological model and multispectral imagery. JGR Solid earth 112(B5):B05419 
Raetzo H, Lateltin O, Bollinger D, Tripet J (2002) Hazard assessment in Switzerland-Codes of Practice for mass movements. Bull Eng Geol Environ 61(3):263-268

Rüeger JM (2002) Refractive index formulae for radio waves. In: Proceedings, FIG Technical Program, XXII FIG international congress, Washington DC, USA

Saastamoinen J (1973) Contribution to the theory of atmospheric refraction. In three parts. B Géod 105, 106, 107:279-298, 383-397, 13-34

Siddique MA, Strozzi T, Hajnsek I, Frey O (2018) A case study on the correction of atmospheric phases for SAR tomography in mountainous regions. IEEE Trans Geosci Remote Sens 99 (online first): $1-16$

Strozzi T, Ambrosi C, Raetzo H (2013) Interpretation of aerial photographs and satellite SAR interferometry for the inventory of landslides. Remote Sens 5(5):2554-2570

Troller M (2004) GPS based determination of the integrated and spatially distributed water vapor in the troposphere. Geodätischgeophysikalische Arbeiten in der Schweiz 67

van der Hoeven A, Hanssen RF, Ambrosius B (2002) Tropospheric delay estimation and analysis using GPS and SAR interferometry. Phys Chem Earth 27(4-5):385-390

Vedel H (2000) Conversion of WGS84 geometric heights to NWP model HIRLAM geopotential heights. Scientific Report 00-04, Danish Meteorological Institute

Vedel H, Huang XY (2004) Impact of ground based GPS data on numerical weather prediction. J Meteorol Soc Jpn 82(1B):459-472

Wicks CW, Dzurisin D, Ingebritsen S, Thatcher W, Lu Z, Iverson J (2002) Magmatic activity beneath the quiescent Three Sisters volcanic center, central Oregon Cascade Range, USA. Geophys Res Lett 29(7):26-1-26-4
Wilgan K, Hurter F, Geiger A, Rohm W, Bosy J (2017a) Tropospheric refractivity and zenith path delays from least-squares collocation of meteorological and GNSS data. J Geod 91(2):117-134

Wilgan K, Hadas T, Hordyniec P, Bosy J (2017b) Real-time precise point positioning augmented with high-resolution numerical weather prediction model. GPS Solut 21(3):1341-1353

Williams S, Bock Y, Fang P (1998) Integrated satellite interferometry: Tropospheric noise, GPS estimates and implications for interferometric synthetic aperture radar products. JGR Solid Earth 103(B11):27051-27067

Zheng F, Lou Y, Gu S, Gong X, Shi C (2017) Modeling tropospheric wet delays with national GNSS reference network in China for BeiDou precise point positioning. J Geod (online first):1-16

Zus F, Wickert J, Bauer HS, Schwitalla T, Wulfmeyer V (2011) Experiments of GPS slant path data assimilation with an advanced MM5 4DVAR system. Meteorologische Z 20(2):173-184 